\title{
MAMAP - a new spectrometer system for column-averaged methane and carbon dioxide observations from aircraft: retrieval algorithm and first inversions for point source emission rates
}

\author{
T. Krings ${ }^{1}$, K. Gerilowski ${ }^{1}$, M. Buchwitz ${ }^{1}$, M. Reuter ${ }^{1}$, A. Tretner ${ }^{2}$, J. Erzinger $^{2}$, D. Heinze ${ }^{3}$, U. Pflüger ${ }^{4}$, \\ J. P. Burrows ${ }^{1}$, and H. Bovensmann ${ }^{1}$ \\ ${ }^{1}$ University of Bremen, Institute of Environmental Physics, P.O. Box 330440, 28334 Bremen, Germany \\ ${ }^{2}$ Helmholtz Centre Potsdam - GFZ German Research Centre for Geosciences, Telegrafenberg, 14473 Potsdam, Germany \\ ${ }^{3}$ Vattenfall Europe Generation AG, Vom-Stein-Straße 39, 03050 Cottbus, Germany \\ ${ }^{4}$ Deutscher Wetterdienst (DWD), Frankfurter Straße 135, 63067 Offenbach, Germany
}

Received: 29 March 2011 - Published in Atmos. Meas. Tech. Discuss.: 21 April 2011

Revised: 10 August 2011 - Accepted: 26 August 2011 - Published: 6 September 2011

\begin{abstract}
MAMAP is an airborne passive remote sensing instrument designed to measure the dry columns of methane $\left(\mathrm{CH}_{4}\right)$ and carbon dioxide $\left(\mathrm{CO}_{2}\right)$. The MAMAP instrument comprises two optical grating spectrometers: the first observing in the short wave infrared band (SWIR) at 1590$1690 \mathrm{~nm}$ to measure $\mathrm{CO}_{2}$ and $\mathrm{CH}_{4}$ absorptions, and the second in the near infrared (NIR) at 757-768 nm to measure $\mathrm{O}_{2}$ absorptions for reference/normalisation purposes. MAMAP can be operated in both nadir and zenith geometry during the flight. Mounted on an aeroplane, MAMAP surveys areas on regional to local scales with a ground pixel resolution of approximately $29 \mathrm{~m} \times 33 \mathrm{~m}$ for a typical aircraft altitude of $1250 \mathrm{~m}$ and a velocity of $200 \mathrm{~km} \mathrm{~h}^{-1}$. The retrieval precision of the measured column relative to background is typically $\lesssim 1 \%(1 \sigma)$. MAMAP measurements are valuable to close the gap between satellite data, having global coverage but with a rather coarse resolution, on the one hand, and highly accurate in situ measurements with sparse coverage on the other hand. In July 2007, test flights were performed over two coal-fired power plants operated by Vattenfall Europe Generation AG: Jänschwalde (27.4 $\mathrm{MtCO}_{2} \mathrm{yr}^{-1}$ ) and Schwarze Pumpe (11.9 $\mathrm{MtCO}_{2} \mathrm{yr}^{-1}$ ), about $100 \mathrm{~km}$ southeast of Berlin, Germany. By using two different inversion approaches, one based on an optimal estimation scheme to fit Gaussian plume models from multiple sources to the data, and another using a simple Gaussian integral method, the emission rates can be determined and compared with emis-
\end{abstract}

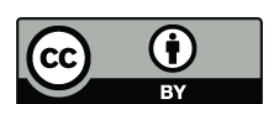

Correspondence to: $\mathrm{T}$. Krings (thomas.krings@iup.physik.unibremen.de) sions reported by Vattenfall Europe. An extensive error analysis for the retrieval's dry column results $\left(X_{C_{2}}\right.$ and $\left.X \mathrm{CH}_{4}\right)$ and for the two inversion methods has been performed. Both methods - the Gaussian plume model fit and the Gaussian integral method - are capable of deriving estimates for strong point source emission rates that are within $\pm 10 \%$ of the reported values, given appropriate flight patterns and detailed knowledge of wind conditions.

\section{Introduction}

Methane $\left(\mathrm{CH}_{4}\right)$ and carbon dioxide $\left(\mathrm{CO}_{2}\right)$ are the two most important anthropogenic greenhouse gases contributing to climate change. Since the industrial era (before $1750 \mathrm{AD}$ ), $\mathrm{CO}_{2}$ has increased by about $35 \%$ from $280 \mathrm{ppm}$ to about $379 \mathrm{ppm}$ in 2005 (Forster et al., 2007), where half of the increase took place during the last $30 \mathrm{yr}$. Up to three quarters of this increase have been attributed to combustion of fossil fuels (e.g. in power plants but also steel plants, etc.), gas flaring (at refineries, oil platforms, etc.) and cement production (Forster et al., 2007). However, despite their importance, these anthropogenic $\mathrm{CO}_{2}$ point sources have not been well quantified. For example, for coal-fired power plants which are among the strongest emitters for $\mathrm{CO}_{2}$ (e.g. EPER, 2004), Ackerman and Sundquist (2008) found that emission estimates for individual US power plants differ by about $20 \%$ and recommend different independent approaches for a more reliable quantification of emissions. Usually, power plant emissions are estimated from emission factors based e.g. on power generation or stack measurements.

Published by Copernicus Publications on behalf of the European Geosciences Union. 
In the European Union (EU) the greenhouse gas emission allowance trading scheme (European Commision, 2007) gives mandatory guidelines on how greenhouse gas emissions should be reported. For strong emitters as a result of combustion ( $>500 \mathrm{kt} \mathrm{CO}_{2} \mathrm{yr}^{-1}$ ), the uncertainty in fuel consumption which serves as input data for the greenhouse gas calculations is allowed to be $1.5 \%$ at maximum. This EU Emission Trading System (ETS) legislation is overseen by the national authorities. An additional error is caused by the uncertainty of power generation $(\sim 1 \%)$ and of the emission and oxidation factors. However, Evans et al. (2009) noticed that the uncertainties of the EU ETS are not referring to the accuracy ("closeness to truth") but to the precision ("repeatability of the data"). Furthermore, Evans et al. (2009) observed at different coal-fired power plants a negative bias of emissions calculated from emission factors compared to emissions derived from continuous emission monitoring systems (CEMS) of $15 \%$ and more.

Currently, these and other point sources cannot be resolved by existing satellite instruments nor can they be monitored by available surface observation networks but imperatively require further investigation (NRC, 2010).

Methane has the second largest effect on anthropogenic radiative forcing next to $\mathrm{CO}_{2}$. It is less abundant but exhibits a global warming potential per unit mass that is more than 20 times higher than that for $\mathrm{CO}_{2}$ (Forster et al., 2007; Shindell et al., 2009). Methane mole fractions increased from $750 \mathrm{ppb}$ to $1774 \mathrm{ppb}$ (in the last $250 \mathrm{yr}$ ) and the sources can be divided into anthropogenic and natural. Natural sources of methane are dominated by spatially extended wetlands (100 (92-232) $\left.\mathrm{Tg} \mathrm{CH}_{4} \mathrm{yr}^{-1}\right)$ and geological local sources (19 (12.4-48.2) $\mathrm{Tg} \mathrm{CH}_{4} \mathrm{yr}^{-1}$ ) like seeps and mud volcanoes, and increasingly also destabilised methane hydrates. The latter may be further enhanced by global warming (Wuebbles and Hayhoe, 2002). Anthropogenic sources like landfills $\left(61(40-100) \mathrm{Tg} \mathrm{CH}_{4} \mathrm{yr}^{-1}\right)$, rice agriculture $\left(60(25-90) \mathrm{Tg} \mathrm{CH}_{4} \mathrm{yr}^{-1}\right)$, biomass burning (50 (27-80) $\mathrm{Tg} \mathrm{CH}_{4} \mathrm{yr}^{-1}$ ), ruminant animals (81 (65100) $\mathrm{Tg} \mathrm{CH}_{4} \mathrm{yr}^{-1}$ ) and release of $\mathrm{CH}_{4}$ due to fossil fuel production and distribution (106 (46-174) $\mathrm{Tg} \mathrm{CH}_{4} \mathrm{yr}^{-1}$ ) (Wuebbles and Hayhoe, 2002) are usually localised. All in all, natural and anthropogenic localised sources account for about $40 \%$ of the total yearly methane emissions of 503 (410660) $\mathrm{Tg} \mathrm{CH}_{4}$ (Wuebbles and Hayhoe, 2002). Landfills alone account for more than $12 \%$ of the total yearly emissions.

The quantification of local sources and sinks of the greenhouse gases $\mathrm{CO}_{2}$ and especially $\mathrm{CH}_{4}$ still has significant gaps in spatial distribution and magnitude as well as in their temporal development. Babilotte et al. (2010) compared five different state-of-the-art measurement techniques (in-situ and remote sensing) to quantify the local $\mathrm{CH}_{4}$ emissions of a particular landfill in France. The methods under investigation were a tracer gas technique, laser radial plume mapping, inverse modelling technique, differential absorption LIDAR (DIAL) and helicopter borne spectroscopy. The estimated emissions differed by an order of magnitude. The main problem for the inversion modelling, for instance, is probably the limited accessibility of sampling locations depending on wind direction and available roads. Babilotte et al. (2010) conclude that further research on each method is necessary to provide reliable results for emission rates. Similar results were obtained by Börjesson et al. (2000) who found that $\mathrm{CH}_{4}$ emission estimates for a Swedish landfill differ by a factor of 4 between tracer gas techniques and closed chamber measurements. Using the example of Canadian natural gas processing plants and a refinery, Chambers and Strosher (2006a,b) showed that emission estimates may be 4-9 times higher when computed using DIAL instruments compared to calculations from emission factors.

A remote sensing instrument that can retrieve precise column information with a footprint size in the order of the source heterogeneity, and is able to measure on a regional scale at an ample speed can add significant knowledge to our understanding of surface fluxes of the two most important anthropogenic greenhouse gases. The MAMAP instrument was built to improve the quantification and understanding of current $\mathrm{CO}_{2}$ and $\mathrm{CH}_{4}$ sources and to provide the opportunity of a monitoring system for local source regions which are vulnerable and influenced by global warming.

The present manuscript is the second of two describing the MAMAP instrument and showing first results of measurements and inversions for point source emission rates. In the first (Gerilowski et al., 2011), a detailed instrument description including a thorough precision analysis and a discussion of the range of application was given.

In this manuscript, the focus addresses the retrieval algorithm applied to obtain trace gas column information from spectroscopic measurements and the subsequent inversion for point source emission rates. The inversion is demonstrated at two strong $\mathrm{CO}_{2}$ point sources: the power plants Jänschwalde and Schwarze Pumpe close to Berlin, Germany, which were targets for a MAMAP test flight in summer 2007.

Section 2 briefly introduces the instrument, followed by a description of the modified WFM-DOAS retrieval algorithm (see Sect. 3) including a short assessment of altitude sensitivity and potential error sources like aerosols, clouds, albedo, solar zenith angle, aircraft altitude, surface elevation and water vapour content. Section 4 deals with the inversion for emission rates of the power plants (see Sect. 4.1), which have been obtained via two different approaches: the Gaussian plume inversion (see Sect. 4.2) and the integral method (see Sect. 4.3), both using wind data from the COSMO-DE model of the German Weather Service (DWD) (see Sect. 4.4). Data quality is addressed in Sect. 4.5 and the inversion results (see Sect. 4.6) followed by an initial error analysis (see Sect. 4.7) are then compared with independent data computed from emission factors being provided from Vattenfall Europe Generation AG. Finally, a summary and conclusions are given in Sect. 5. 


\section{Instrument}

The MAMAP (Methane Airborne Mapper) instrument is a passive remote sensing instrument designed for airborne applications to measure columns of $\mathrm{CH}_{4}$ and $\mathrm{CO}_{2}$. It was developed in a cooperation between the University of Bremen and the Helmholtz Centre Potsdam, GFZ German Research Centre for Geosciences. MAMAP measures in the short wave infrared (SWIR) and in the near infrared (NIR) spectral region using two separate grating spectrometers. The SWIR spectrometer measures in the region of $1590 \mathrm{~nm}$ to $1690 \mathrm{~nm}$ with a resolution of $0.82 \mathrm{~nm}$ FWHM covering $\mathrm{CH}_{4}$ and $\mathrm{CO}_{2}$ absorption bands. To provide a reference measurement a NIR imaging pushbroom spectrometer measures the $\mathrm{O}_{2} \mathrm{~A}$ absorption band between $757 \mathrm{~nm}$ and $768 \mathrm{~nm}$ with a resolution of $0.46 \mathrm{~nm}$ FWHM. The instantaneous field of view (IFOV) of the SWIR spectrometer is about $1.34^{\circ} \times 0.02^{\circ}$ (cross track $\times$ along track). For an exposure time of $\sim 0.6 \mathrm{~s}$, a typical aircraft altitude of about $1.25 \mathrm{~km}$ and $200 \mathrm{~km} \mathrm{~h}^{-1}$ ground speed, this results in a ground pixel size of about $29 \mathrm{~m} \times 33 \mathrm{~m}$, where the along track extension is primarily determined by ground speed and exposure time. The parameters above are a valid configuration in most cases where the surface reflectance, termed albedo in this manuscript, is not significantly below 0.18 (assuming a Lambertian reflector), which is about the albedo of vegetation. Over surfaces with lower albedo, i.e. mainly water, the exposure time has to be extended accordingly. The retrieval precision of the measured column is typically about $1 \%(1 \sigma)$ for $\sim 0.6 \mathrm{~s}$ integration time, currently limited by spectrometer effects. This matter has been resolved in subsequent flights not the subject of this publication. The goal is to achieve precisions below $1 \%$ and shot noise limited retrieval. A detailed discussion on these topics can be found in Gerilowski et al. (2011).

\section{Retrieval}

A retrieval algorithm is used to convert the spectral radiances measured by MAMAP to the trace gas column information of interest. For the processing of MAMAP data, a modified version of the Weighting Function Modified Differential Optical Absorption Spectroscopy (WFM-DOAS) algorithm (Buchwitz et al., 2000) is used to obtain vertical column information of $\mathrm{CH}_{4}, \mathrm{CO}_{2}$ and also $\mathrm{O}_{2}$.

The standard DOAS technique assumes that the absorption cross sections are independent of height. However, this is usually not valid for the strong absorbers in the infrared. Thus, WFM-DOAS additionally takes into account the pressure and temperature dependency of the absorption cross sections using linearisation points.

WFM-DOAS has been successfully applied to scientific retrieval of $\mathrm{CO}_{2}$ and $\mathrm{CH}_{4}$ column information (Buchwitz et al., 2005a,b; Schneising et al., 2008, 2009) from the
SCIAMACHY satellite sensor on board Envisat (Bovensmann et al., 1999).

SCIAMACHY's WFM-DOAS uses a look-up table approach with multi-dimensional interpolation for SZA, albedo, surface elevation. Water vapour is iteratively fitted before the final trace gas fit of e.g. $\mathrm{CH}_{4}$ or $\mathrm{CO}_{2}$. The MAMAP test flights described here cover only narrow regions and rather short time spans compared to SCIAMACHY observations, so that only a specific set of parameters for SZA, albedo, surface elevation, water vapour, etc. have been applied instead of an extended look-up table. However, for future surveys being larger in time and space, look-up tables can be used accordingly.

\subsection{Algorithm}

As for SCIAMACHY, the MAMAP version of the WFMDOAS algorithm is based on a least squares fit of the logarithmic simulated radiance spectrum to the measurements. The fit parameters are:

1. desired atmospheric parameters, i.e. partial or total columns of $\mathrm{CH}_{4}, \mathrm{CO}_{2}$ and $\mathrm{O}_{2}$,

2. additional trace gas atmospheric parameters for spectrally interfering gases (water vapour),

3. other atmospheric parameters (temperature) and

4. a low order polynomial in wavelength to account for spectrally smooth varying parameters which are not explicitly modelled or not well enough known. These parameters include for example the MAMAP absolute radiometric calibration function, aerosol scattering and absorption parameters and the surface spectral reflectance,

5. shift and squeeze parameters from an iterative wavelength calibration procedure,

6. and an alternating function accounting for a detector pixel odd even correction (compare Gerilowski et al., 2011).

The logarithm of the spectrum can be expressed as a linearised radiative transfer model plus a low order polynomial $P_{\lambda}$ :

$$
\begin{aligned}
\ln R_{\lambda}^{\mathrm{mea}}= & \ln R_{\lambda}^{\mathrm{mod}}(\overline{\mathbf{c}})+\sum_{j} W_{\lambda, \bar{c}_{j}} \frac{c_{j}-\bar{c}_{j}}{\bar{c}_{j}} \\
& +P_{\lambda}(\mathbf{a})+\epsilon_{\lambda}
\end{aligned}
$$

On the left hand side of this equation there is the logarithm of the measured spectral radiance $R_{\lambda}^{\text {mea }}$ at a wavelength $\lambda$. On the right hand side there is the WFM-DOAS linearised radiative transfer model, the low order polynomial $P_{\lambda}$ with the free fit parameters a and an error term $\epsilon_{\lambda}$. The expression $R_{\lambda}^{\bmod }(\overline{\mathbf{c}})$ denotes the radiative transfer model result at 
the linearisation point $\overline{\mathbf{c}}$. The vector-valued $\overline{\mathbf{c}}$ consists of typical values for relevant atmospheric parameters. These "first guess" values are referred to as $\bar{c}_{j}$. The second term on the right hand side describes the linearised model corrections depending on the fit parameters $c_{j}$. To each $\bar{c}_{j}$ exists a corresponding fit parameter $c_{j}$. The column weighting functions $W_{\lambda, \bar{c}_{j}}$ denote the derivatives of the radiance with respect to fit parameters $c_{j}$. They are computed by adding up all relevant atmospheric layer weighting functions $W_{\lambda, \bar{c}_{j}, z}$ :

$W_{\lambda, \bar{c}_{j}}=\sum_{z=z_{\text {low }}}^{z_{\text {up }}} W_{\lambda, \bar{c}_{j}, z}$

where $z_{\text {low }}$ and $z_{\text {up }}$ denote the lower and upper limit of the relevant atmospheric layers. For a general MAMAP retrieval, the altitude range would reach from the lowest atmospheric layer to the top of atmosphere. As a consequence, the retrieval algorithm does not resolve different altitude levels but shifts the mean profile as a whole. The results of the algorithm are height averaged increased or decreased profile scaling factors (PSF) or a profile shift (in case of temperature).

The atmospheric layer weighting functions are computed as:

$$
W_{\lambda, \bar{c}_{j}, z}=\left.\frac{\partial \ln R_{\lambda}}{\partial \ln c_{z}}\right|_{\bar{c}(z)} \cdot \Delta_{z}
$$

This is basically the relative change of radiance due to a relative change of the according parameter $c$ at altitude $z$ times the quadrature weight $\Delta_{z}$. The quadrature weights essentially correspond to the geometrical thickness of the layers of the model atmosphere.

Both the model radiances and the weighting functions are computed with the radiative transfer model SCIATRAN (Rozanov et al., 2005) using the HITRAN 2008 spectroscopic data base (Rothman et al., 2009) and a sun spectrum by Livingston and Wallace (1991).

The error term $\epsilon_{\lambda}$ in Eq. (1) accounts for all wavelength dependent differences between the measurement and the model which cannot be modelled or cannot be modelled without approximations (e.g. aerosol effects). In an ideal case, the error term is identical with the instrument's detector noise.

Equation (1) can be expressed as a vector equation of the following form:

$\boldsymbol{y}-\mathbf{A} \cdot \boldsymbol{x}=\epsilon$

with each vector component corresponding to a specific wavelength $\lambda$. Here, A denotes a matrix whose columns consist of the weighting functions $W_{\lambda, \bar{c}_{j}}$ and of the polynomial base functions. The vector $\boldsymbol{y}$ is built up by the differences of logarithmic radiances of measurement and model at the linearisation point $\bar{c}$. The parameters $\boldsymbol{x}$, corresponding to the (relative) change in the atmospheric parameters and the poly- nomial coefficients, respectively, can be obtained by a least squares fit minimising the sum of the squared errors:

$$
\sum_{i=\lambda_{\min }}^{\lambda_{\max }} \epsilon_{i}^{2}=\|\epsilon\|^{2}=\|\boldsymbol{y}-\mathbf{A} \cdot \boldsymbol{x}\|^{2}
$$

The solution $\hat{\boldsymbol{x}}$ is then given by:

$$
\hat{\boldsymbol{x}}=\left(\mathbf{A}^{T} \mathbf{A}\right)^{-1} \mathbf{A}^{t} \boldsymbol{y}
$$

The remaining measurement error $\epsilon$ is a measure for the quality of the spectral fit, which in practice is not only determined by noise but also influenced by systematic errors (e.g. spectrometer slit function uncertainties or errors in spectroscopic parameters). Since the systematic measurement errors are not known, the statistical errors of fit parameter $j$ have to be estimated from the residual $\epsilon$ :

$\sigma_{\hat{x}_{j}}=\sqrt{\left(\mathbf{A}^{T} \mathbf{A}\right)_{j, j}^{-1} \frac{\|\epsilon\|^{2}}{m-n}}$

where $m$ is the number of spectral points used for the fit, $n$ the number of fit parameters and $m-n$ the number of degrees of freedom of the linear least squares problem.

For the interpretation of the MAMAP measurements with respect to sources and sinks of the greenhouse gases $\mathrm{CO}_{2}$ and $\mathrm{CH}_{4}$, the column averaged dry air mole fractions (in ppm for $\mathrm{CO}_{2}$ or ppb for $\mathrm{CH}_{4}$ ) are the preferred quantity rather than the total columns (in molecules $\mathrm{cm}^{-2}$ ). This is because dry air mole fractions are less affected by changes in surface topography, pressure and flight altitude compared to the absolute column.

To convert the obtained total columns, additional knowledge of the dry air column, i.e. the total number of molecules in the air column neglecting water molecules, is necessary. This knowledge can be obtained in several ways:

1. by using simultaneous measurements of the oxygen $\left(\mathrm{O}_{2}\right)$ column,

2. by using another well-mixed gas whose mole fraction is quite well known and varies significantly less than the trace gas of interest, or

3. by considering external information on surface pressure obtained from e.g. meteorological analysis. However, very high resolution surface pressure data would be required in this case, especially in areas with high topographic variations.

Successful utilisation of the $\mathrm{O}_{2}$ column (1) (in the case of MAMAP obtained from the $\mathrm{O}_{2} \mathrm{~A}$ band spectrally located at about $760 \mathrm{~nm}$ ) has been demonstrated, for example, in Schneising et al. (2008) for SCIAMACHY column-averaged $\mathrm{CO}_{2}$ retrieval. The mole fraction of $\mathrm{O}_{2}$ in dry air is well known $(20.95 \%)$ and fairly constant in space and time up to about $100 \mathrm{~km}$. However, due to the spectral distance of the 
$\mathrm{O}_{2} \mathrm{~A}$ band at $760 \mathrm{~nm}$ and the $\mathrm{CO}_{2}$ and $\mathrm{CH}_{4}$ absorption bands located at about $1.6 \mu \mathrm{m}$, light paths will be different if not all scattering parameters are known. This can lead to total column retrieval errors (see Schneising et al., 2008, 2009, for a discussion).

This can be avoided when using another well-mixed gas as reference (2) which is measured spectrally close to the trace

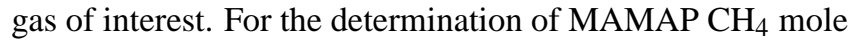
fractions, the $\mathrm{CO}_{2}$ mole fractions can be assumed in many cases to be effectively constant and well mixed compared to $\mathrm{CH}_{4}$ - at least in regions without large temporal or spatial $\mathrm{CO}_{2}$ variations. Due to the spectral closeness, the photon paths can be assumed to be similar for both gases causing light path errors to cancel to a large extent when computing the column-averaged dry air mole fractions $\left(\mathrm{XCH}_{4}\right)$ :

$$
\mathrm{XCH}_{4}=\frac{\mathrm{CH}_{4}^{\text {column }}}{\mathrm{CO}_{2}^{\text {column }} / \mathrm{CO}_{2}^{\text {aver. mole fraction }}}
$$

This is also done for $\mathrm{CH}_{4}$ mole fractions obtained from SCIAMACHY (Frankenberg et al., 2005; Schneising et al., 2009).

In case of strong $\mathrm{CO}_{2}$ sources like the power plants in this study away from strong local methane sources, $\mathrm{CH}_{4}$ can be used to determine mole fractions for carbon dioxide $\mathrm{XCO}_{2}$ accordingly:

$$
X \mathrm{CO}_{2}=\frac{\mathrm{CO}_{2}^{\text {column }}}{\mathrm{CH}_{4}^{\text {column }} / \mathrm{CH}_{4}^{\text {aver. mole fraction }}}
$$

But also $\mathrm{CH}_{4}$ area sources such as wetlands will not significantly bias the result of a strong $\mathrm{CO}_{2}$ point source. For example, a $10 \mathrm{~km}$ wide wetland upwind of the point source will only result in a columnar $\mathrm{CH}_{4}$ increase of $0.03 \%-$ $0.06 \% \mathrm{CH}_{4}$, assuming a high summer wetland emission rate of 50-100 $\mathrm{mg} \mathrm{CH}_{4} \mathrm{~m}^{-2}$ day-1 (e.g. Ringeval et al., 2010, for wetland emission rates), a wind speed of $2 \mathrm{~m} \mathrm{~s}^{-1}$ and a background column of about $9.75 \mathrm{~g} \mathrm{CH}_{4} \mathrm{~m}^{-2}$.

For this study, the average mole fractions $\mathrm{CO}_{2}^{\text {aver. mole fraction }}$ and $\mathrm{CH}_{4}^{\text {aver. mole fraction }}$ were assumed to be $\approx 380 \mathrm{ppm}$ and $\approx 1.7 \mathrm{ppm}$ (with a surface value of $1.780 \mathrm{ppm}$ ), respectively. The corresponding vertical profiles determine the linearisation point for the radiative transfer model. The retrieval results are normalised prior to the inversion process. Hence, the choice of background concentrations has no direct impact on the emission rate estimates.

We also prefer this method to using external surface pressure data (3) because of the higher accuracy that can be obtained if light path errors can be accounted for. The feasibility, however, depends strongly on the actual variability of $\mathrm{CO}_{2}$ and $\mathrm{CH}_{4}$.

\subsection{Altitude sensitivity}

As can be seen from Eq. (2), the MAMAP WFM-DOAS retrieval does not resolve different altitude levels. However, the

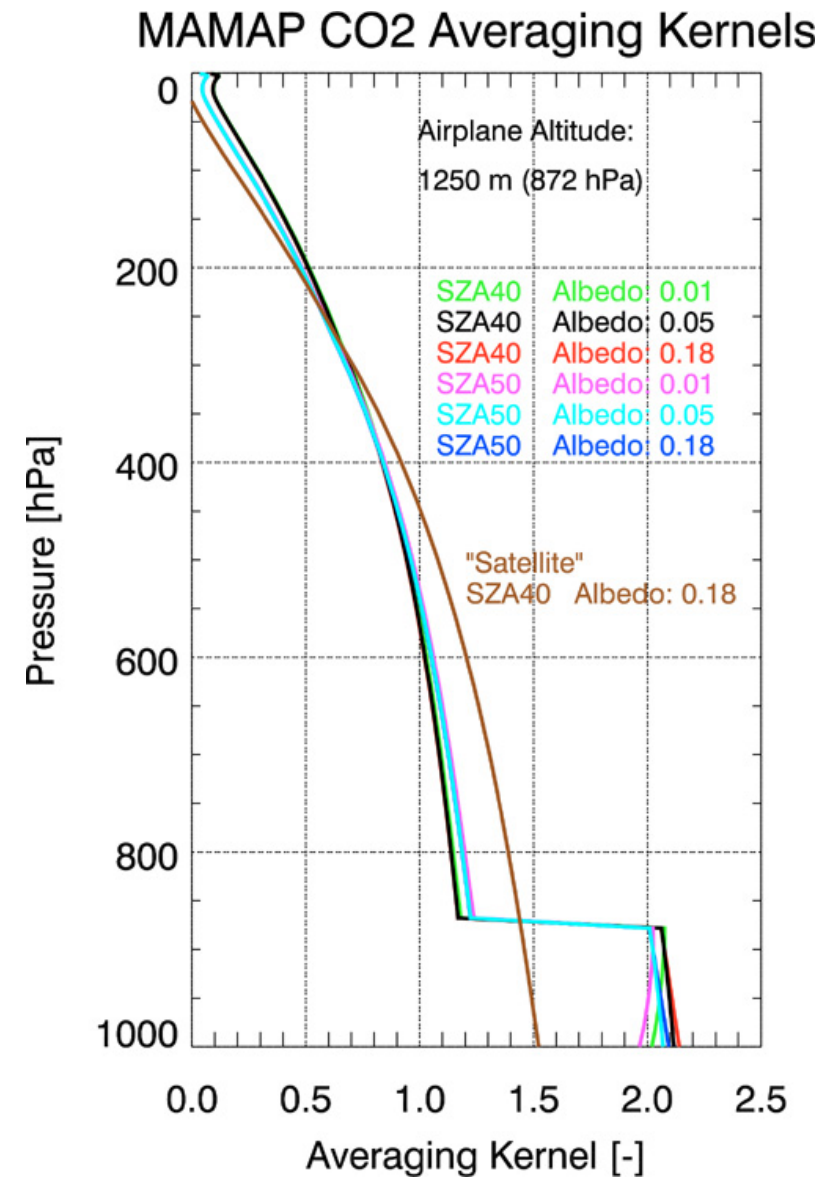

Fig. 1. $\mathrm{CO}_{2}$ averaging kernels of the MAMAP WFM-DOAS retrieval for an aircraft altitude of $1250 \mathrm{~m}$ and different albedos and solar zenith angles. For comparison, averaging kernels for a hypothetical aircraft altitude of $1000 \mathrm{~km}$ (i.e. satellite altitude) are also shown.

retrieval has different sensitivities for different altitude layers. This behaviour can be characterised by the so called column averaging kernels (AK) as a function of altitude. They are defined as the variation of the retrieval parameter (i.e. the trace gas column) $c_{\text {retrieved }}$ as a result of a perturbation of the true subcolumn $c_{\text {true }}(z)$ at altitude $z$ :

$\operatorname{AK}(z)=\frac{\partial c_{\text {retrieved }}}{\partial c_{\text {true }}(z)}$

The AK for MAMAP have been computed by retrieving trace gas columns from measurement simulations that have been perturbed at various altitude levels $z$. An averaging kernel value equal to unity at a certain altitude indicates that the perturbation was correctly retrieved by the algorithm. Values lower or higher than unity indicate a decreased or increased sensitivity. In particular, there is a sharp step in the averaging kernels at the aeroplane altitude (see Fig. 1). Below the aeroplane altitude, the averaging kernels are increased by a factor of about 2 (for low aircraft altitudes). This is due to the fact 
Table 1. Conversion factors for retrieval output (compare Sect. 3.2), assuming an aircraft altitude of $1.25 \mathrm{~km}$ and that all deviations from standard mean column occurred below the aircraft.

\begin{tabular}{|c|c|c|c|c|}
\hline \multirow{2}{*}{$\begin{array}{l}\text { Solar zenith } \\
\text { angle }\left[^{\circ}\right]\end{array}$} & \multirow{2}{*}{$\begin{array}{c}\text { Surface } \\
\text { albedo [-] }\end{array}$} & \multirow{2}{*}{$\begin{array}{l}\text { Aerosol } \\
\text { type }\end{array}$} & \multicolumn{2}{|c|}{ Conversion factor $[-]$} \\
\hline & & & $\mathrm{CH}_{4}$ & $\mathrm{CO}_{2}$ \\
\hline \multirow{6}{*}{40} & \multirow{2}{*}{0.1} & urban & 0.580 & 0.477 \\
\hline & & background & 0.582 & 0.478 \\
\hline & \multirow{2}{*}{0.18} & urban & 0.578 & 0.475 \\
\hline & & background & 0.581 & 0.477 \\
\hline & \multirow{2}{*}{0.25} & urban & 0.577 & 0.474 \\
\hline & & background & 0.580 & 0.477 \\
\hline \multirow{6}{*}{50} & \multirow{2}{*}{0.1} & urban & 0.603 & 0.488 \\
\hline & & background & 0.604 & 0.489 \\
\hline & \multirow{2}{*}{0.18} & urban & 0.600 & 0.487 \\
\hline & & background & 0.603 & 0.488 \\
\hline & \multirow{2}{*}{0.25} & urban & 0.599 & 0.485 \\
\hline & & background & 0.602 & 0.488 \\
\hline \multirow{6}{*}{60} & \multirow{2}{*}{0.1} & urban & 0.629 & 0.502 \\
\hline & & background & 0.630 & 0.502 \\
\hline & \multirow{2}{*}{0.18} & urban & 0.626 & 0.500 \\
\hline & & background & 0.628 & 0.501 \\
\hline & \multirow{2}{*}{0.25} & urban & 0.625 & 0.498 \\
\hline & & background & 0.628 & 0.501 \\
\hline
\end{tabular}

that light from the sun passes through the absorber below the aircraft twice - once before and once after surface reflection. The higher the aircraft flies, the less pronounced the step becomes, since the height averaged AK are about unity.

For a typical MAMAP measurement, elevated or decreased trace gas concentrations can be expected mainly below the aircraft due to activity at the surface, e.g. power plants emitting $\mathrm{CO}_{2}$ or landfills releasing $\mathrm{CH}_{4}$. Since the retrieval is not height sensitive, the measurements will be weighted with the mean averaging kernel (ideally being close to unity). If the concentration changes occur evenly at all altitude levels, this gives the correct result. For changes only below the aircraft, this has to be accounted for e.g. by a conversion factor. Otherwise, the column averaged mole fraction variations from the retrieval appear about twice as high as they actually are. This conversion factor $k$ can be computed by:

$k=\frac{1}{\overline{\mathrm{AK}_{\text {low }}}}$

where $\overline{\mathrm{AK}_{\text {low }}}$ denotes the mean averaging kernel of altitude layers below the aircraft. Table 1 gives examples of conversion factors for various conditions. Note that the conversion factors given here are not identical to those in Gerilowski et al. (2011) since an improved radiative transfer has been applied for the retrieval resulting in modified averaging kernels and hence, also in slightly modified conversion factors $k$. The improvements include the update from the HITRAN 2004 (Rothman et al., 2005) to the HITRAN 2008 spectroscopic data base (Rothman et al., 2009), an altitude grid with higher vertical resolution in lower altitudes and a more complex aerosol profile.

The actual variation in the column can then be calculated by using observation geometry and averaging kernels:

$\Delta c=(c-\bar{c})_{\text {corrected }}=k \cdot(c-\bar{c})$

Alternatively, it is possible to fix the column above the aircraft to background and retrieve and shift only below. However for this approach to be accurate, detailed knowledge of the above column is required. MAMAP's zenith observation mode potentially offers the opportunity to obtain and incorporate this information.

\subsection{Sensitivity and error analysis}

To assess the sensitivity of the derived total column data of $\mathrm{CO}_{2}, \mathrm{CH}_{4}$ and $\mathrm{O}_{2}$ to atmospheric parameters, retrieval simulations with different radiative transfer simulations have been performed. If not stated otherwise, the retrieval was conducted using an albedo of 0.18 (assuming a Lambertian reflector), a solar zenith angle of $40^{\circ}$ and an OPAC (Hess et al., 1998) continental background aerosol scenario (99.998\% water soluble) as it is also used for recent WFMDOAS SCIAMACHY satellite data retrieval of $\mathrm{CO}_{2}$ and $\mathrm{CH}_{4}$ (Schneising et al., 2011).

Tables 2-7 show the relative error on the result of the retrieved background total columns of $\mathrm{CO}_{2}, \mathrm{CH}_{4}$ and 
Table 2. Solar zenith angle sensitivity of total column concentrations and their ratios for different aircraft altitudes, if the true solar zenith angle is deviating from the $40^{\circ}$ assumed for the retrieval.

\begin{tabular}{ccrrrrr}
\hline Aircraft & Solar zenith & \multicolumn{5}{c}{ Sensitivities } \\
\cline { 3 - 7 } altitude [km] & angle [ $\left.{ }^{\circ}\right]$ & $\mathrm{CO}_{2}[\%]$ & $\mathrm{CH}_{4}[\%]$ & $\mathrm{O}_{2}[\%]$ & $\mathrm{CO}_{2} / \mathrm{CH}_{4}[\%]$ & $\mathrm{CO}_{2} / \mathrm{O}_{2}[\%]$ \\
\hline \multirow{3}{*}{0.85} & 35.0 & -5.97 & -6.02 & -5.73 & 0.05 & -0.25 \\
& 40.0 & 0.00 & 0.00 & 0.00 & 0.00 & 0.00 \\
& 45.0 & 7.44 & 7.56 & 7.22 & -0.11 & 0.21 \\
\hline \multirow{3}{*}{1.25} & 35.0 & -5.74 & -5.82 & -5.46 & 0.08 & -0.30 \\
& 40.0 & 0.00 & 0.00 & 0.00 & 0.00 & 0.00 \\
& 45.0 & 7.15 & 7.31 & 6.88 & -0.15 & 0.25 \\
\hline \multirow{3}{*}{3.0} & 35.0 & -4.99 & -5.14 & -4.66 & 0.16 & -0.35 \\
& 40.0 & 0.00 & 0.00 & 0.00 & 0.00 & 0.00 \\
& 45.0 & 6.23 & 6.47 & 5.91 & -0.23 & 0.30 \\
\hline \multirow{3}{*}{4.5} & 35.0 & -4.57 & -4.75 & -4.27 & 0.19 & -0.31 \\
& 40.0 & 0.00 & 0.00 & 0.00 & 0.00 & 0.00 \\
& 45.0 & 5.72 & 5.98 & 5.42 & -0.25 & 0.28 \\
\hline
\end{tabular}

Table 3. Aerosol sensitivity of total column concentrations and their ratios for an aircraft altitude of $1.25 \mathrm{~km}$. Lowtran (LT, using HenyeyGreenstein phase functions for a background scenario and a scenario with extreme aerosol load in the boundary layer (BL)) and OPAC (using Mie phase functions) aerosol scenarios have been used (see Hess et al., 1998; Schneising et al., 2008; Schneising, 2009).

\begin{tabular}{lrrrrr}
\hline \multirow{2}{*}{$\begin{array}{l}\text { Aerosol } \\
\text { scenario }\end{array}$} & $\mathrm{CO}_{2}[\%]$ & $\mathrm{CH}_{4}[\%]$ & $\mathrm{O}_{2}[\%]$ & $\mathrm{CO}_{2} / \mathrm{CH}_{4}[\%]$ & $\mathrm{CO}_{2} / \mathrm{O}_{2}[\%]$ \\
\hline LT background & 1.35 & 1.17 & 0.94 & 0.18 & 0.41 \\
LT extreme in BL & 3.34 & 2.88 & 0.11 & 0.44 & 3.23 \\
OPAC background & 0.00 & 0.00 & 0.00 & 0.00 & 0.00 \\
OPAC urban & 0.38 & 0.33 & 0.28 & 0.05 & 0.10 \\
OPAC desert & 1.26 & 1.07 & 0.50 & 0.18 & 0.76 \\
\hline
\end{tabular}

$\mathrm{O}_{2}$ and their ratios for variations of different atmospheric parameters.

Table 2 shows the dependence on the solar zenith angle (SZA) for different aircraft altitudes, if $40^{\circ}$ is assumed for the retrieval but the true SZA is different. It is obvious that there is a rather large error on the single gas columns, decreasing with higher aircraft altitude, since the fraction of the wrongly assumed light path (before reflection on the ground) becomes lower. The SZA can be determined very precisely when geolocation (e.g. by GPS) and time of measurement are known and can be considered for the retrieval reference scenario. However, in case of flights with a short temporal duration, a single reference scenario can be used if the ratio of e.g. $\mathrm{CO}_{2} / \mathrm{CH}_{4}$ is applied, as has been done for the analysis of this study. This method is also superior to the $\mathrm{O}_{2}$ proxy method, provided that $\mathrm{CH}_{4}$ variations are negligible.

The same accounts for the aerosol dependency (Table 3), which is rather low in the ratios with $\mathrm{CH}_{4}$. This is also confirmed in a simulation considering actual aerosol deployment in a power plant's vicinity (compare Sect. 4.7.3). Usage of a standard background scenario or the urban polluted in industrial areas as general reference scenario seems justified.

Another parameter giving rise to potential errors is the surface elevation (Table 4). Unaccounted elevations of $100 \mathrm{~m}$ can lead to a bias of $-0.34 \%$ in the ratios. However, surface elevation is a well known parameter if geolocation is known. Note that in this study the area is rather flat and no significant errors from surface elevation are to be expected.

For the retrieval, solely an albedo of 0.18 was applied assuming a Lambertian reflector and no spectral dependency. Obviously, this is not true for real surfaces. To assess the influence of different surface types on the standard retrieval, surface spectral reflectances of various surfaces have been simulated for two different aerosol scenarios (Table 5). The surface types chosen here (soil, sand, snow, deciduous vegetation, conifer vegetation, rangeland and ocean) are based on the ASTER Spectral Library through the courtesy of the Jet Propulsion Laboratory, California Institute of Technology, Pasadena, California (@1999, California Institute of Technology) and the Digital Spectral Library 06 of the US 
Table 4. Surface elevation sensitivity of total column concentrations and their ratios for an aircraft altitude of $1.25 \mathrm{~km}$ and a solar zenith angle (SZA) of $40^{\circ}$.

\begin{tabular}{crrrrr}
\hline Surface & \multicolumn{5}{c}{ Sensitivities } \\
\cline { 2 - 6 } elevation $[\mathrm{m}]$ & $\mathrm{CO}_{2}[\%]$ & $\mathrm{CH}_{4}[\%]$ & $\mathrm{O}_{2}[\%]$ & $\mathrm{CO}_{2} / \mathrm{CH}_{4}[\%]$ & $\mathrm{CO}_{2} / \mathrm{O}_{2}[\%]$ \\
\hline 0 & 0.00 & 0.00 & 0.00 & 0.00 & 0.00 \\
25 & -0.63 & -0.54 & -0.83 & -0.09 & 0.20 \\
50 & -1.25 & -1.09 & -1.66 & -0.16 & 0.42 \\
75 & -1.87 & -1.63 & -2.49 & -0.24 & 0.64 \\
100 & -2.50 & -2.17 & -3.31 & -0.34 & 0.84 \\
125 & -3.12 & -2.70 & -4.13 & -0.43 & 1.05 \\
150 & -3.74 & -3.24 & -4.95 & -0.52 & 1.27 \\
200 & -4.97 & -4.31 & -6.59 & -0.69 & 1.73 \\
\hline
\end{tabular}

Table 5. Sensitivity to surface spectral albedo (surface type) reproduced from the ASTER Spectral Library through the courtesy of the Jet Propulsion Laboratory, California Institute of Technology, Pasadena, California (@1999, California Institute of Technology) and the Digital Spectral Library 06 of the US Geological Survey in the same form as used by Reuter et al. (2010). Assumed solar zenith angle was $40^{\circ}$ and the aircraft altitude was $1.25 \mathrm{~km}$.

\begin{tabular}{clrrrrr}
\hline \multirow{2}{*}{$\begin{array}{c}\text { Aerosol } \\
\text { scenario }\end{array}$} & Surface & \multicolumn{5}{c}{ Sensitivities } \\
\cline { 2 - 7 } & type & $\mathrm{CO}_{2}[\%]$ & $\mathrm{CH}_{4}[\%]$ & $\mathrm{O}_{2}[\%]$ & $\mathrm{CO}_{2} / \mathrm{CH}_{4}[\%]$ & $\mathrm{CO}_{2} / \mathrm{O}_{2}[\%]$ \\
\hline \multirow{5}{*}{ OPAC background } & Soil (Mollisol) & 0.26 & -0.23 & -0.26 & 0.03 & 0.52 \\
& Sand (Entisol) & 0.51 & 0.45 & 0.50 & 0.06 & -0.01 \\
& Medium Snow & -0.26 & -0.05 & 2.40 & -0.21 & -2.60 \\
& Deciduous (Aspen) & -0.04 & -0.08 & 0.43 & 0.04 & -0.47 \\
& Conifers-Meadow & -0.09 & -0.12 & -0.09 & 0.03 & 0.00 \\
& Rangeland & 0.10 & 0.08 & 0.07 & 0.02 & -0.03 \\
& Open Ocean & -0.55 & -0.46 & -2.80 & -0.09 & 2.31 \\
\hline \multirow{5}{*}{ OPAC urban } & Soil (Mollisol) & 0.39 & 0.34 & -0.37 & 0.05 & 0.76 \\
& Sand (Entisol) & 0.76 & 0.67 & 0.66 & 0.09 & 1.43 \\
& Medium Snow & -0.52 & -0.17 & 2.96 & -0.35 & -3.38 \\
& Deciduous (Aspen) & -0.09 & -0.10 & 0.57 & 0.01 & -0.66 \\
& Conifers-Meadow & -0.18 & -0.18 & -0.12 & 0.00 & -0.06 \\
& Rangeland & 0.14 & 0.13 & 0.09 & 0.01 & 0.05 \\
& Open Ocean & -1.00 & -0.85 & -4.09 & -0.15 & 3.22 \\
\hline
\end{tabular}

Geological Survey in the same manner as used by Reuter et al. (2010). Where for the $\mathrm{O}_{2}$ proxy method biases in case of MAMAP retrievals can be quite high, they are rather low for the $\mathrm{CH}_{4}$ proxy method for both aerosol scenarios (background and urban). The largest errors are caused by snow due to the very low albedo in the SWIR band.

Subvisual (and visual) cirrus can be a major problem for remote sensing application since they are difficult to identify but can have a significant impact on the light path. Several cirrus cloud scenarios have been tested (Table 6) with cirrus cloud base heights of 6.0, 9.0,12.0, 15.0, 18.0 and $21.0 \mathrm{~km}$ altitude. Each cirrus layer was assumed to be $500 \mathrm{~m}$ thick. The tested optical thickness and the corresponding ice water paths were $0.01,0.05,0.10,0.30,0.70$ and $0.31,1.54$, $3.05,9.20,21.45 \mathrm{~g} \mathrm{~m}^{-2}$, respectively. The ratio with $\mathrm{CH}_{4}$ also proves to be very robust in this case. For an optically thick (0.05) subvisual cirrus, errors to be expected range between $-0.05 \%$ and $0.05 \%$ with respect to the background column.

The aircraft altitude obviously has an impact on the retrieval results, as well. For the current analysis the principal altitude of observation during the flight was kept constant at $1.25 \mathrm{~km}$. This altitude was hence also chosen as default for the reference radiative transfer simulation in the retrieval. Table 7 shows the errors to be expected if the actual aircraft altitude is differing from the reference altitude.

Also, the water vapour influence on the retrieval result has been investigated and has proven to be rather low (Table 8). Even for a strong enhancement of e.g. a factor of 3 compared to background, the error on the ratio $\mathrm{CO}_{2} / \mathrm{CH}_{4}$ is only $+0.13 \%$, showing that there is almost no interference between water vapour and the $\mathrm{XCO}_{2}$ product. 
Table 6. Sensitivity to cirrus clouds for an aircraft altitude of $1.25 \mathrm{~km}$, a solar zenith angle of $40^{\circ}$ and an albedo of 0.18 assuming a cirrus geometrical thickness of $500 \mathrm{~m}$.

\begin{tabular}{|c|c|c|c|c|c|c|c|}
\hline \multirow{2}{*}{$\begin{array}{c}\text { Optical } \\
\text { thickness } \\
{[-]}\end{array}$} & \multirow{2}{*}{$\begin{array}{c}\text { Ice } \\
\text { water } \\
\text { Path }\left[\mathrm{g} \mathrm{m}^{-2}\right]\end{array}$} & \multirow{2}{*}{$\begin{array}{c}\text { Cloud } \\
\text { base } \\
\text { Height }[\mathrm{km}]\end{array}$} & \multicolumn{5}{|c|}{ Sensitivities } \\
\hline & & & $\mathrm{CO}_{2}[\%]$ & $\mathrm{CH}_{4}[\%]$ & $\mathrm{O}_{2}[\%]$ & $\mathrm{CO}_{2} / \mathrm{CH}_{4}[\%]$ & $\mathrm{CO}_{2} / \mathrm{O}_{2}[\%]$ \\
\hline \multirow{6}{*}{0.01} & \multirow{6}{*}{0.31} & 6.0 & 0.26 & 0.25 & 0.10 & 0.01 & 0.16 \\
\hline & & 9.0 & 0.29 & 0.29 & 0.09 & 0.00 & 0.20 \\
\hline & & 12.0 & 0.30 & 0.31 & 0.10 & -0.01 & 0.20 \\
\hline & & 15.0 & 0.31 & 0.32 & 0.10 & -0.01 & 0.21 \\
\hline & & 18.0 & 0.31 & 0.33 & 0.10 & -0.02 & 0.21 \\
\hline & & 21.0 & 0.33 & 0.31 & 0.10 & -0.02 & 0.23 \\
\hline \multirow{6}{*}{0.05} & \multirow{6}{*}{1.54} & 6.0 & 1.20 & 1.15 & 0.49 & 0.05 & 0.71 \\
\hline & & 9.0 & 1.34 & 1.32 & 0.49 & 0.02 & 0.85 \\
\hline & & 12.0 & 1.40 & 1.42 & 0.49 & -0.02 & 0.91 \\
\hline & & 15.0 & 1.42 & 1.46 & 0.49 & -0.04 & 0.93 \\
\hline & & 18.0 & 1.43 & 1.48 & 0.49 & -0.05 & 0.94 \\
\hline & & 21.0 & 1.49 & 1.44 & 0.49 & -0.05 & 1.00 \\
\hline \multirow{6}{*}{0.10} & \multirow{6}{*}{3.05} & 6.0 & 2.18 & 2.09 & 0.95 & 0.08 & 1.22 \\
\hline & & 9.0 & 2.44 & 2.42 & 0.95 & 0.02 & 1.48 \\
\hline & & 12.0 & 2.56 & 2.59 & 0.96 & -0.03 & 1.58 \\
\hline & & 15.0 & 2.60 & 2.68 & 0.96 & -0.07 & 1.62 \\
\hline & & 18.0 & 2.61 & 2.72 & 0.96 & -0.10 & 1.63 \\
\hline & & 21.0 & 2.73 & 2.62 & 0.96 & -0.11 & 1.75 \\
\hline \multirow{6}{*}{0.30} & \multirow{6}{*}{9.20} & 6.0 & 5.17 & 5.02 & 2.63 & 0.15 & 2.47 \\
\hline & & 9.0 & 5.84 & 5.85 & 2.66 & -0.01 & 3.10 \\
\hline & & 12.0 & 6.12 & 6.28 & 2.66 & -0.15 & 3.37 \\
\hline & & 15.0 & 6.22 & 6.49 & 2.66 & -0.25 & 3.47 \\
\hline & & 18.0 & 6.25 & 6.59 & 2.66 & -0.32 & 3.50 \\
\hline & & 21.0 & 6.64 & 6.26 & 2.65 & -0.36 & 3.89 \\
\hline \multirow{6}{*}{0.70} & \multirow{6}{*}{21.45} & 6.0 & 8.90 & 8.74 & 5.29 & 0.15 & 3.43 \\
\hline & & 9.0 & 10.04 & 10.24 & 5.35 & -0.18 & 4.45 \\
\hline & & 12.0 & 11.53 & 10.06 & 5.35 & -0.48 & 5.87 \\
\hline & & 15.0 & 10.70 & 11.44 & 5.34 & -0.67 & 5.09 \\
\hline & & 18.0 & 10.76 & 11.63 & 5.39 & -0.78 & 5.10 \\
\hline & & 21.0 & 11.72 & 10.78 & 5.38 & -0.85 & 6.02 \\
\hline
\end{tabular}

Table 7. Sensitivity to aircraft altitude sensitivity uncertainty for an albedo of 0.18 and a reference altitude of $1.25 \mathrm{~km}$.

\begin{tabular}{rrrrrr}
\hline$\Delta$ Aircraft & \multicolumn{5}{c}{ Sensitivities } \\
\cline { 2 - 6 } altitude $[\mathrm{m}]$ & $\mathrm{CO}_{2}[\%]$ & $\mathrm{CH}_{4}[\%]$ & $\mathrm{O}_{2}[\%]$ & $\mathrm{CO}_{2} / \mathrm{CH}_{4}[\%]$ & $\mathrm{CO}_{2} / \mathrm{O}_{2}[\%]$ \\
\hline-400 & -3.81 & -3.33 & -4.57 & -0.49 & 0.80 \\
-250 & -2.35 & -2.06 & -2.80 & -0.30 & 0.46 \\
-100 & -1.40 & -1.23 & -1.65 & -0.17 & 0.26 \\
-50 & -0.46 & -0.41 & -0.54 & -0.05 & 0.08 \\
0 & 0.00 & 0.00 & 0.00 & 0.00 & 0.00 \\
50 & 0.46 & 0.40 & 0.54 & 0.06 & -0.08 \\
100 & 1.37 & 1.20 & 1.58 & 0.17 & -0.21 \\
250 & 2.26 & 1.99 & 2.60 & 0.26 & -0.33 \\
400 & 3.15 & 2.77 & 3.59 & 0.37 & -0.43 \\
\hline
\end{tabular}


Table 8. Sensitivity of total column concentrations and their ratios to water vapour for a solar zenith angle (SZA) of $40^{\circ}$ and an aircraft altitude of $1.25 \mathrm{~km}$. The $\mathrm{H}_{2} \mathrm{O}$ scaling factors denote the scaling of the background water vapour profile e.g. due to emissions of water vapour from a power plant's cooling towers.

\begin{tabular}{crrrrr}
\hline \multirow{2}{*}{$\mathrm{H}_{2} \mathrm{O}$} & \multicolumn{5}{c}{ Sensitivities } \\
\cline { 2 - 6 } scaling & $\mathrm{CO}_{2}[\%]$ & $\mathrm{CH}_{4}[\%]$ & $\mathrm{O}_{2}[\%]$ & $\mathrm{CO}_{2} / \mathrm{CH}_{4}[\%]$ & $\mathrm{CO}_{2} / \mathrm{O}_{2}[\%]$ \\
\hline 0.5 & 0.00 & -0.01 & 0.00 & 0.01 & 0.00 \\
1.0 & 0.00 & 0.00 & 0.00 & 0.00 & 0.00 \\
1.5 & 0.00 & -0.01 & 0.00 & 0.01 & 0.00 \\
2.0 & -0.03 & -0.05 & -0.01 & 0.02 & -0.02 \\
3.0 & -0.13 & -0.26 & -0.01 & 0.13 & -0.12 \\
4.0 & -0.29 & -0.59 & -0.02 & 0.30 & -0.27 \\
\hline
\end{tabular}

Table 9. Typical uncertainties to be generally expected in a standard retrieval of $\mathrm{XCO}_{2}$ using the $\mathrm{CH}_{4}$ proxy method for an albedo of 0.18 , an aerosol background scenario and a reference aircraft altitude of $1.25 \mathrm{~km}$.

\begin{tabular}{llc}
\hline Parameter & Expected variation & Uncertainty $\mathrm{CO}_{2} / \mathrm{CH}_{4}[\%]$ \\
\hline Solar zenith angle & $\pm 5^{\circ}$ & $\sim-0.15 \%$ \\
Aerosol & urban vs. background & $\sim+0.05 \%$ \\
Surface elevation & $+50 \mathrm{~m}$ & $\sim-0.16 \%$ \\
$\mathrm{H}_{2} \mathrm{O}$ profile & $\times 2$ & $\sim+0.02 \%$ \\
Spectral albedo & Aspen vs. 0.18 & $\sim+0.04 \%$ \\
Cirrus clouds (subvis.) & no cirrus vs. AOT 0.1, CTH $12 \mathrm{~km}$ & $\sim-0.03 \%$ \\
Aircraft altitude & $\pm 50 \mathrm{~m}$ & $\sim+0.06 \%$ \\
\hline & total uncertainty estimate: & $\sim 0.24 \%$ \\
\hline
\end{tabular}

Table 9 lists typical uncertainties that may generally be expected for a retrieval of $\mathrm{XCO}_{2}$ using the $\mathrm{CH}_{4}$ proxy method for small temporal and spatial scales. The total uncertainty estimate based on Table 9 is then $\sim 0.24 \%$, computed as the root of the sum of individual squared uncertainties.

\section{Inversion of power plant emission rate}

\subsection{Target description}

During a test flight with a Cessna 207 aircraft close to Berlin on 26 July 2007, several overpasses with the MAMAP instrument were performed over the coal-fired power plants Jänschwalde and Schwarze Pumpe, both operated by the Vattenfall Europe Generation AG, Cottbus, Germany. The power plants are situated south-east of Berlin in the Lausitz lignite mining district with a distance of about $35 \mathrm{~km}$ in between (see Fig. 2).

Jänschwalde is a $3000 \mathrm{MW}$ power plant consisting of 6 units, each producing 500 MW of energy mainly via burning of lignite. Flue gas is emitted through 6 out of a total of 9 cooling towers along with water vapour formerly trapped in the lignites, from burning hydrogen and from the flue gas desulphurisation. The remaining 3 cooling towers only emit water vapour. Annual $\mathrm{CO}_{2}$ emissions are about $27.4 \mathrm{MtCO}_{2} \mathrm{yr}^{-1}$ and Jänschwalde power plant is listed among the top 10 of $\mathrm{CO}_{2}$ producing power plants (data from CARMA, www.CARMA.org). The cooling towers reach about $113 \mathrm{~m}$ height.

The power plant Schwarze Pumpe is also fired with lignite and produces a total of $1600 \mathrm{MW}$ of energy from two units. Two huge cooling towers emit water vapour and the flue gas. Schwarze Pumpe has annual emissions of about $11.9 \mathrm{MtCO}_{2} \mathrm{yr}^{-1}$ (data from CARMA, www.CARMA.org). The cooling towers have a ground diameter of $130 \mathrm{~m}$ and are about $140 \mathrm{~m}$ high.

The day of measurement had favourable weather conditions characterised by clear sky with only slight cirrus and low to medium wind speeds close to ground. Almost no clouds due to possible condensation of water vapour were forming above the cooling towers .

Detailed information on the power plants' emission rates have been obtained from data collected routinely by Vattenfall. The temporal resolution of the provided data is $15 \mathrm{~min}$ and has been converted to a yearly value for comparison in Table 10.

\subsection{Gaussian plume optimal estimation inversion}

The $\mathrm{CO}_{2}$ concentrations downwind of a point source - such as the coal-fired power plants under investigation here - can 
Table 10. Emission rate results for the power plants Jänschwalde and Schwarze Pumpe using the Gaussian plume model and the Gaussian integral inversion methods. For the Gaussian plume model, the result for the retrieved stability parameter $a$ and the statistical errors according to Eq. (21) are also given.

\begin{tabular}{|c|c|c|c|c|c|c|c|}
\hline \multirow[b]{2}{*}{ Power plant } & \multirow{2}{*}{$\begin{array}{c}\begin{array}{c}\text { Reported } \\
\text { emissions }\end{array} \\
{\left[\mathrm{MtCO}_{2} \mathrm{yr}^{-1}\right]}\end{array}$} & \multicolumn{4}{|c|}{ Plume inversion } & \multicolumn{2}{|c|}{ Integral inversion } \\
\hline & & $\begin{array}{c}\text { absolute } \\
{\left[\mathrm{MtCO}_{2} \mathrm{yr}^{-1}\right]}\end{array}$ & $\begin{array}{l}\text { relative to } \\
\text { reported }[-]\end{array}$ & $\begin{array}{l}\text { \# pixels used } \\
\text { for inversion }\end{array}$ & $\begin{array}{c}\text { stability } \\
\text { parameter [-] }\end{array}$ & $\begin{array}{c}\text { absolute } \\
{\left[\mathrm{MtCO}_{2} \mathrm{yr}^{-1}\right]}\end{array}$ & $\begin{array}{l}\text { relative to } \\
\text { reported [-] }\end{array}$ \\
\hline Jänschwalde & 24.125 & $\begin{array}{l}26.131 \\
\pm 1.838\end{array}$ & $\begin{array}{c}1.083 \\
\pm 7.03 \%\end{array}$ & 174 & $\begin{array}{c}327.4 \\
\pm 10.2 \%\end{array}$ & 24.066 & 0.998 \\
\hline Schwarze Pumpe & 13.035 & $\begin{array}{c}11.865 \\
\pm 1.473\end{array}$ & $\begin{array}{c}0.910 \\
\pm 12.41 \%\end{array}$ & 209 & $\begin{array}{c}357.3 \\
\pm 13.6 \%\end{array}$ & 11.748 & 0.901 \\
\hline
\end{tabular}

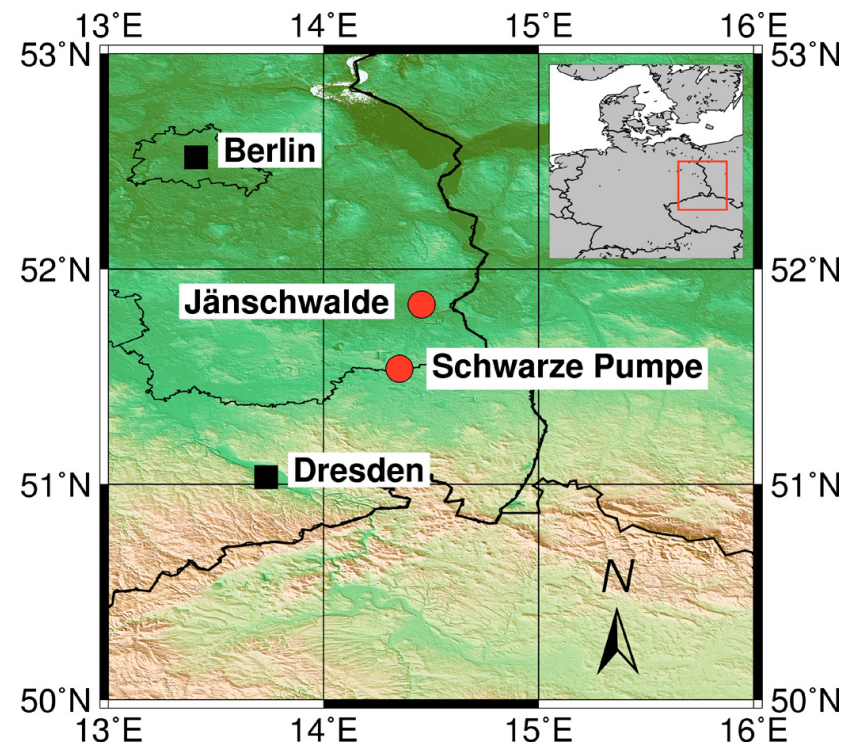

Fig. 2. Map of locations of power plants Jänschwalde and Schwarze Pumpe in eastern Germany close to Berlin. The distance between the two power plants is about $35 \mathrm{~km}$. (Topographic data has been obtained from the Shuttle Radar Topography Mission (SRTM) version 2.1 (http://dds.cr.usgs.gov/srtm/version2_1/), a collaborative effort from NASA, NGA as well as the German and Italian Space Agencies).

be estimated by a quasi-stationary Gaussian plume model (Sutton, 1932). Since MAMAP measures columns, the plume model equation can be integrated to the total vertical column $V$ (in $\mathrm{g} \mathrm{m}^{-2}$ ) and equals:

$V(x, y)=\frac{F}{\sqrt{2 \pi} \sigma_{y}(x) u} \mathrm{e}^{-\frac{1}{2}\left(\frac{y}{\sigma_{y}(x)}\right)^{2}}$

where the $\mathrm{x}$-direction is parallel to the wind direction and the $y$-direction is perpendicular to the wind direction. The advantage of the vertically integrated form is the independence of the actual vertical distribution of the plume. Only in terms of wind shear is the distribution of importance. The vertical column $V$ depends on the emission rate $F$ (in $\mathrm{g} \mathrm{s}^{-1}$ ), the across wind distance $y$, wind speed $u$, and the horizontal dispersion coefficient (standard deviation) in y-direction $\sigma_{y}$. The standard deviation $\sigma_{y}=\sigma_{y}(x)$ is a function of the along wind distance $x$ and depends on the atmospheric stability parameter $a$ (Masters, 1998, and references therein):

$\sigma_{y}=a \cdot x^{0.894}$

where $x$ must be specified in kilometres to obtain $\sigma_{y}$ in meters. For example, for stability class A (very unstable) Masters (1998) gives:

$a=213$.

Using this Gaussian plume model for a single point source with slightly unstable atmospheric conditions (stability $B$, $a=156)$ and a wind speed of $2 \mathrm{~m} \mathrm{~s}^{-1}$, a source strength of $6000 \mathrm{~g} \mathrm{CO}_{2} \mathrm{~s}^{-1}$ or $10 \mathrm{~g} \mathrm{CH}_{4} \mathrm{~s}^{-1}$ is required to obtain a $1 \%$ column increase for $\mathrm{CO}_{2}$ or $\mathrm{CH}_{4}$, as the case may be, in at least one MAMAP footprint pixel of approximately $30 \mathrm{~m} \times 30 \mathrm{~m}$.

To simulate an emission source with a cross section $y_{0}$ at the plume's origin - in contrast to a point source - an offset $x_{0}$ is added in Eq. (14):

$\sigma_{y}=a\left(x+x_{0}\right)^{0.894}$

The offset distance $x_{0}$ can be computed as follows:

$x_{0}=\left(\frac{y_{0}}{4 a}\right)^{\frac{1}{0.894}}$

The factor of 4 is introduced so that the source width is described by a $\pm 2 \sigma$ environment, i.e. about $95.45 \%$ of total emissions are confined along the source width at distance $x=0 \mathrm{~m}$ from the source.

When having a network of $N$ sources, the vertical column $V$ is a result of all contributing sources $F_{j}$ and Eq. (13) changes to:

$V(x, y)=\sum_{j=1}^{N} \frac{F_{j}}{\sqrt{2 \pi} \sigma_{y}\left(x_{j}\right) u} \mathrm{e}^{-\frac{1}{2}\left(\frac{y_{j}}{\sigma_{y}\left(x_{j}\right)}\right)^{2}}$ 
where $x_{j}, y_{j}$ denote the distance to the corresponding source location of $F_{j}$.

To obtain estimates of source emission rates $F_{j}$ from measured vertical columns $V(x, y)$, a linear optimal estimation scheme can be used. In this study, the stability parameter $a$ is retrieved additionally so that an iterative scheme has to be applied due to the non-linearity of the inverse problem. A detailed description of theory and application of optimal estimation methods can be found in Rodgers (2000). In general, a forward model is fitted to data with respect to given a priori information. Here, optimal estimation finds the solution of maximum probability by minimising the following cost function $\chi$ for all $F_{j}$ and $a$ simultaneously:

$$
\begin{aligned}
\chi= & \left(\boldsymbol{V}_{\text {meas }}-\boldsymbol{V}_{\text {mod }}\right)^{T} \mathbf{S}_{\epsilon}^{-1}\left(\boldsymbol{V}_{\text {meas }}-\boldsymbol{V}_{\text {mod }}\right) \\
+ & \left(\boldsymbol{R}-\boldsymbol{R}_{a}\right)^{T} \mathbf{S}_{a}^{-1}\left(\boldsymbol{R}-\boldsymbol{R}_{a}\right)
\end{aligned}
$$

where $\boldsymbol{R}$ is the state vector with entries $F_{j}, a$ to be retrieved and $\mathbf{K}$ is the Jacobian or weighting function matrix with entries $K_{i, j}=\partial V_{i} / \partial R_{j}$. Note that $V(x, y)$ has been re-indexed to a 1-dimensional vector with entries $V_{i}$. Furthermore, $\boldsymbol{V}_{\text {meas }}$ denotes the measured columns with the error covariance matrix $\mathbf{S}_{\epsilon}$, and $\boldsymbol{R}_{\boldsymbol{a}}$ the a priori information of source emission rates and atmospheric stability with the associated covariance matrix $\mathbf{S}_{\mathbf{a}}$. The forward model $\boldsymbol{V}_{\mathbf{m o d}}(\boldsymbol{R})$ is a function of the state vector elements $F_{j}$ and $a$ according to Eqs. (18) and (16).

If there was no a priori information, i.e. the uncertainties in $\mathbf{S}_{\mathbf{a}}$ were arbitrarily large, Eq. (19) would lead to a general weighted least squares solution as it was used in Bovensmann et al. (2010) for single point source satellite applications for CarbonSat. However, a priori information may become necessary for an increasing number of sources $F_{j}$, especially if they are located close to each other. To avoid unphysical ambiguities resulting in negative emission rates of individual sources, the a priori information can be used to constrain the emission rates to non-negative values. In the presence of strong sinks this has to be reconsidered, but for the targets of interest in this paper, source strengths exceed possible sinks by several orders of magnitudes. Another possibility to avoid unphysical results is to couple the emissions, e.g. assuming them from each stack of a power plant to be equal, which was done for this study. Since all units of both power plants respectively were running at the same level, this is a reasonable assumption.

The iterative maximum a posteriori solution $\boldsymbol{R}_{n+1}$ minimising Eq. (19) using an initial value $\boldsymbol{R}_{n}$ is given by (Rodgers, 2000):

$$
\begin{aligned}
\boldsymbol{R}_{n+1}= & \boldsymbol{R}_{a}+\left(\mathbf{S}_{a}^{-1}+\mathbf{K}_{n}^{T} \mathbf{S}_{\epsilon}^{-1} \mathbf{K}_{n}\right)^{-1} \mathbf{K}_{n}^{T} \mathbf{S}_{\epsilon}^{-1} \\
& \cdot\left[\boldsymbol{V}_{\text {meas }}-\boldsymbol{V}_{\text {mod }}\left(\boldsymbol{R}_{n}\right)+\mathbf{K}_{n}\left(\boldsymbol{R}_{n}-\boldsymbol{R}_{a}\right)\right]
\end{aligned}
$$

with the according covariance matrix:

$\mathbf{S}_{n+1}=\left(\mathbf{K}_{n}^{T} \mathbf{S}_{\epsilon}^{-1} \mathbf{K}_{n}+\mathbf{S}_{a}^{-1}\right)^{-1}$
For the present study, convergence is determined to be reached when:

$$
\left(\boldsymbol{R}_{n+1}-\boldsymbol{R}_{n}\right)^{T} \mathbf{S}_{n+1}^{-1}\left(\boldsymbol{R}_{n+1}-\boldsymbol{R}_{n}\right)<\frac{N+1}{100}
$$

\subsection{Gaussian vector integral}

Another way to obtain estimates for emission rates of sources in a distinct area is to take advantage of the Gaussian divergence theorem. It states that the integrated flux $F$ of a vector field $\boldsymbol{G}$ through the closed surface of region $U$ is equal to the emission rate, which can be positive or negative - indicating a source or a sink, respectively:

$$
F=\iiint_{U} \operatorname{div} \boldsymbol{G} d U=\iint_{S} \boldsymbol{G} \cdot d \boldsymbol{S}
$$

Here, the vector field is defined as:

$\boldsymbol{G}=V \boldsymbol{u}$

where $V$ denotes the vertical column of the according trace gas and $\boldsymbol{u}$ the wind speed. With $\boldsymbol{n}$ being the normal vector on the boundary $S$ Eq. (23) becomes in a discrete form:

$$
\begin{aligned}
F & =\iint_{S} V \boldsymbol{u} \cdot \boldsymbol{n} d S \\
& \approx \sum_{i} V_{i} \boldsymbol{u} \cdot \boldsymbol{n}_{\boldsymbol{i}} \Delta S_{i}
\end{aligned}
$$

where $\Delta S_{i}$ is a scalar measure for the length of the boundary segment under consideration. Since $V$ is a measure for the whole column, no vertical transport has to be explicitly accounted for. Furthermore, boundary parts parallel to wind direction can be omitted. Note that no diffusion is taken into account for this very simple approximation.

The boundaries for the actual inversion of the power plant emission rates have been chosen manually following flight tracks upwind and downwind. Values along these boundaries have been assigned by a nearest neighbour approach. See Fig. 3 for the choice of boundaries of this study. The upwind component offers potentially the advantage to distinguish between the source of interest and upwind sources which increase the background level.

However, data quality upwind of the power plants turned out to be very poor. In case of Jänschwalde, sheets of water result in a low signal to noise ratio and a poor fit. Rejection of data from the already very low number of measurements upwind of the power plant can lead to strong biases. Since the data has been normalised and due to the fact that no $\mathrm{CO}_{2}$ source in the order of magnitude of the power plant itself can be expected, the upwind component has been set to background in a first approach. This can be avoided in the future when dedicated flight patterns are performed.

The same accounts for power plant Schwarze Pumpe where the very inhomogeneous area upwind of the power 
plant very likely leads to inhomogeneity effects as have been described in Gerilowski et al. (2011). Gerilowski et al. (2011) also proposed a sensor modification which is currently under development to avoid these problems in future campaigns.

\subsection{Wind data}

Wind speed is a key parameter entering linearly into Eq. (18), i.e. an error of for example $5 \%$ on the knowledge of the wind speed in the respective altitudes will result in a $5 \%$ error on the emission rates. Hence, detailed knowledge of wind speed and also wind direction is essential. Since the flight over the power plants was designed as instrumental performance test, no on-site information of wind speed has been acquired. Instead, wind information from the routine analysis of the numerical weather prediction model COSMO-DE operated by the German Weather Service (DWD) based on the COSMO model (Doms and Schättler, 2002) has been used to analyse the data obtained in terms of emission rates.

COSMO-DE has a spatial resolution of $0.025^{\circ} \times 0.025^{\circ}$. Taking into account that the model computes on a rotated latitude-longitude grid (the north pole is rotated to $170^{\circ}$ west and $40^{\circ}$ north), this results in a resolution of about $2.8 \mathrm{~km} \times 2.8 \mathrm{~km}$. For this study the hourly wind data was only available interpolated to pressure levels $(1000 \mathrm{hPa}$, $950 \mathrm{hPa}, 850 \mathrm{hPa}, 700 \mathrm{hPa}$, etc.). In principle, COSMO-DE output can also be taken directly from the model levels which have a higher vertical resolution with an increasing vertical spacing from $20 \mathrm{~m}$ near ground to about $300 \mathrm{~m}$ at $700 \mathrm{hPa}$.

For the inversion process with the integral and the plume method, it is necessary to have knowledge of wind speed at different altitude levels since the plume rises as a function of distance from the source. The wind speed applied in Eq. (18) refers to an average wind speed throughout the plume extension as required for the quasi stationary assumptions that were made.

Wind directions and wind speeds for different altitudes and at relevant times for the overpasses are depicted in Figs. 4 and 5 , respectively, for the four nearest neighbour data points for each power plant (see Fig. 6).

\subsubsection{Jänschwalde}

From Fig. 4 (top), it can be seen, that according to the COSMO-DE model during the time of the overflight 08:5509:20 UTC, the wind direction was fairly stable at about $235^{\circ}-245^{\circ}$ for all four nearest neighbours of Jänschwalde power plant. This modelled wind direction fits the recorded data, which clearly shows a plume extension in the wind direction of about $228^{\circ}$ (compare Fig. 3), within a few degrees. The deviation might be due to instationarity effects or caused by regional biases in the model and the coarse temporal resolution not capturing variations below one hour.
To obtain an average wind speed from the model data estimated for the whole $\mathrm{CO}_{2}$ plume regarding both vertical and horizontal extension, a typical plume height of about $1.2 \mathrm{~km}$ $\left(\sigma_{z} \approx 300 \mathrm{~m}\right)$ has been assumed, since turbulences downwind of the power plant could be observed from the plane up to more than $1.0 \mathrm{~km}$. Furthermore, the $\mathrm{CO}_{2}$ distribution was assumed to follow a vertical Gaussian profile with the origin at stack height and which is reflected from the ground (compare e.g. Beychok, 2005)

$$
C(z)=\frac{1}{\sigma_{z} \sqrt{2 \pi}}\left(\mathrm{e}^{-\frac{1}{2}\left(\frac{z-h}{\sigma_{z}}\right)^{2}}+\mathrm{e}^{-\frac{1}{2}\left(\frac{z+h}{\sigma_{z}}\right)^{2}}\right)
$$

with the stack height $h=113 \mathrm{~m}$. This confines about $k_{0}=$ $56 \%$ of the $\mathrm{CO}_{2}$ to the lowermost $250 \mathrm{~m}$ and about $k_{1}=44 \%$ to the layer between $250 \mathrm{~m}$ and $1200 \mathrm{~m}$. An average wind speed for the plume has then been computed as follows:

$$
\begin{aligned}
\overline{u_{\mathrm{jw}}} & =\left[\left(k_{0} \cdot \frac{1}{u_{p=1000 \mathrm{hPa}}}\right)+\left(k_{1} \cdot \frac{1}{u_{p=950 \mathrm{hPa}}}\right)\right]^{-1} \\
& \approx\left[\left(56 \% \cdot \frac{1}{3.6 \mathrm{~m} \mathrm{~s}^{-1}}\right)+\left(44 \% \cdot \frac{1}{6.5 \mathrm{~ms}^{-1}}\right)\right]^{-1} \\
& \approx 4.5 \mathrm{~m} \mathrm{~s}^{-1}
\end{aligned}
$$

\subsubsection{Schwarze Pumpe}

Where for Jänschwalde wind conditions were sufficiently stationary, wind direction and wind speed were significantly changing for power plant Schwarze Pumpe at 08:10 08:45 UTC (see Fig. 4, bottom) causing problems for the inversion. To correct for that to some extent, the data has first been rotated to the first wind direction and then bent to fit the second wind direction. Obviously, this is in violation of the quasi stationary conditions needed for Gaussian plume assumptions and will affect the inversion result.

The wind directions and the distance from where to bend the data have been identified empirically from the data, but are in agreement with wind data from the COSMO-DE model. We assumed $210^{\circ}$ for the first wind direction and $234^{\circ}$ for the second. The bending point was determined to be located about $1350 \mathrm{~m}$ downwind of the power plant (compare Fig. 3, right).

An average wind speed has been computed similarly as for the power plant Jänschwalde (see Sect. 4.4.1). Accounting for the according model wind speeds and the greater stack height $(h=140 \mathrm{~m})$ the average wind velocity is:

$$
\begin{aligned}
\overline{u_{\mathrm{sp}}} & =\left[\left(k_{0} \cdot \frac{1}{u_{p=1000 \mathrm{hPa}}}\right)+\left(k_{1} \cdot \frac{1}{u_{p=950 \mathrm{hPa}}}\right)\right]^{-1} \\
& \approx\left[\left(55 \% \cdot \frac{1}{2.5 \mathrm{~m} \mathrm{~s}^{-1}}\right)+\left(45 \% \cdot \frac{1}{5.6 \mathrm{~m} \mathrm{~s}^{-1}}\right)\right]^{-1} \\
& \approx 3.3 \mathrm{~ms}^{-1}
\end{aligned}
$$


Jänschwalde

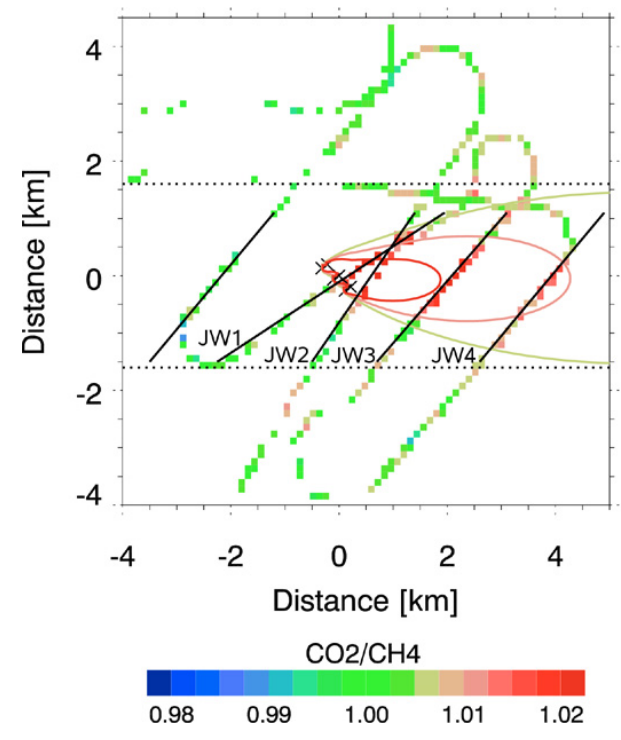

Schwarze Pumpe

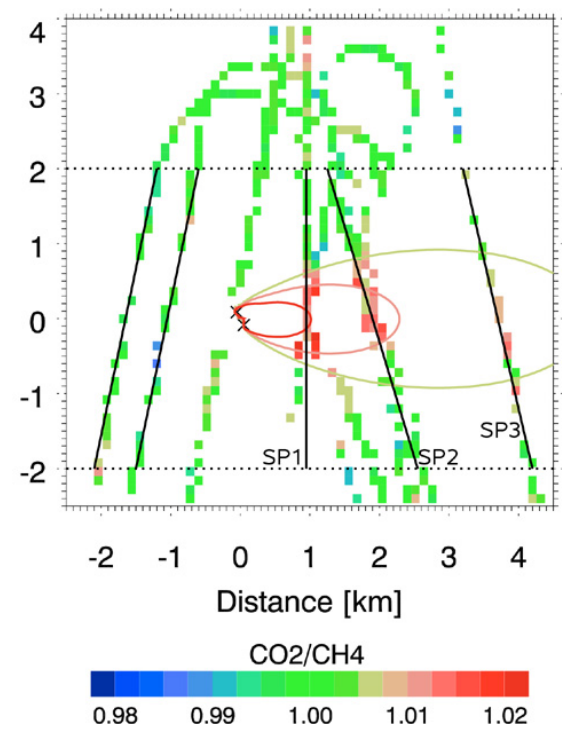

Fig. 3. The figures show the MAMAP data for power plants Jänschwalde and Schwarze Pumpe rotated and bent (only Schwarze Pumpe) to wind direction. The solid black lines (JW1, JW2, ... and SP1, ..) indicate boundaries used for the Gaussian integral inversion whereas the contour lines show the fit result of the Gaussian plume model inversion. The dashed black lines show the area which has been taken into account for the Gaussian plume inversion.

\subsection{Data quality}

To ensure a high level of data quality, MAMAP dark current corrected data has been filtered prior to the inversion. First of all, very low signals (i.e. maximum signal being below 3000 counts) and signals in saturation (i.e. maximum signal at 55000 counts or higher) have been rejected.

Subsequently, the quality of the fit has been assured by applying a filter on the rms (root mean square) between fit and model. In Fig. 7, the rms values have been ordered by size and plotted. The threshold has been set to 0.95 to reject outliers. Furthermore, each burst of 10 single measurement has been accepted as an average only if more than half of the measurements (i.e. 6 or more) passed the rms threshold criteria.

The Gaussian plume inversion has shown to be very stable against variation of the rms threshold reflecting the effective statistical treatment by the optimal estimation method. A variation of the threshold of \pm 0.1 leads to a variation of only $-0.4 \% /+1.2 \%$ on the inversion result in case of Jänschwalde and $-3 \% /-4 \%$ in case of Schwarze Pumpe which has a weaker emission rate. For the Gaussian integral, the variation of the inversion is about $+2.3 \%$ for Jänschwalde and $-1.9 \%$ for Schwarze Pumpe when the rms threshold is increased by +0.1 . A reduction of the threshold causes rather large data gaps which, in combination with the nearest neighbour approach, does not lead do meaningful results.
The Gaussian integral is apparently more affected by the filter threshold. This is also due to the fact that less measurements are taken into account compared to the optimal plume estimation method so that single outliers can have a major effect on the inversion result. This is enhanced by the simple nearest neighbour approach that was chosen as a first approach leading to a nonlinear and partly erratic behaviour in case of sparse data. A dedicated flight pattern for measurements can mitigate the effect in future campaigns.

Finally, all data has been corrected by the conversion factor $k$ according to Eq. (12). In the following $\mathrm{CO}_{2} / \mathrm{CH}_{4}$ always refers to the corrected ratios, i.e. $\mathrm{XCO}_{2}$.

\subsection{Inversion results}

Besides the wind direction and velocity which have to be defined before any inversion can be performed (see Sect. 4.4.1 and 4.4.2), the atmospheric stability and the according stability factor $a$ (see Eq. 14) are also of importance for the Gaussian plume model inversion and are directly retrieved from the data. The measurements over the two power plants were performed in summer in the morning under almost cloud free conditions and hence strong solar insulation. Additionally, the flue gas containing the $\mathrm{CO}_{2}$ is considerably warmer than the surrounding air masses leading to observed turbulences in up to $1.0 \mathrm{~km}$ altitude. Consequently for the inversion, the a priori atmospheric stability was set to very unstable (Stability class A), i.e. $a=213.0$ with an uncertainty of \pm 100.0 . 


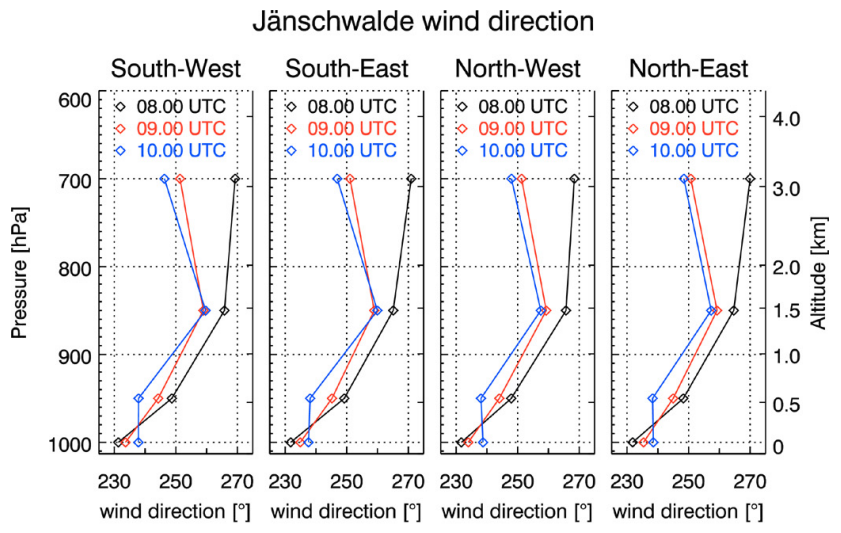

Schwarze Pumpe wind direction

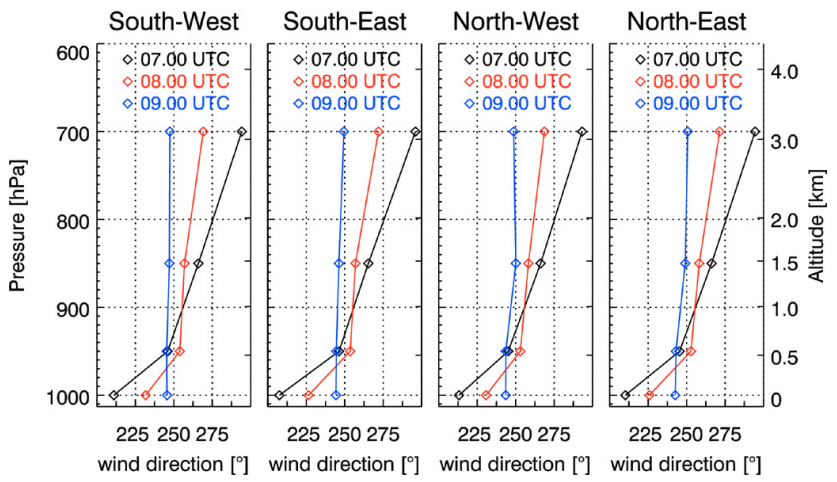

Fig. 4. Figure of wind directions at the sites of the four nearest neighbours of the power plants Jänschwalde and Schwarze Pumpe according to the COSMO-DE model as used for the inversion process.

For the radiative transfer simulation, the aircraft altitude was in a very good approximation $( \pm 35 \mathrm{~m})$ assumed to be constant at $1250 \mathrm{~m}$, the albedo constant at 0.18 and the aerosol scenario was an OPAC urban scenario (Hess et al., $1998)$ with continental polluted aerosol (31.399\% water soluble and $68.6 \%$ soot) in the boundary layer and continental average aerosol (45.79\% water soluble and $54.2 \%$ soot) in the free troposphere (compare also Schneising et al., 2008, 2009; Schneising, 2009).

Figure 3 shows power plant stacks (black crosses), the measurement data gridded to boxes of $120 \mathrm{~m} \times 120 \mathrm{~m}$ and the plume model inversion result as contour lines of total column scaling factors $1.020,1.010$ and 1.005 . Only data between the dashed black lines has been taken into account for the Gaussian plume inversion to obtain a more stable result for the stability parameter $a$ which can be strongly influenced by outliers outside the plume area. With an enhanced instrumental precision, this may become unnecessary in the future. A rather good graphical agreement of model and data can be observed for both Jänschwalde and Schwarze Pumpe power plant. This is confirmed by the cross sections along

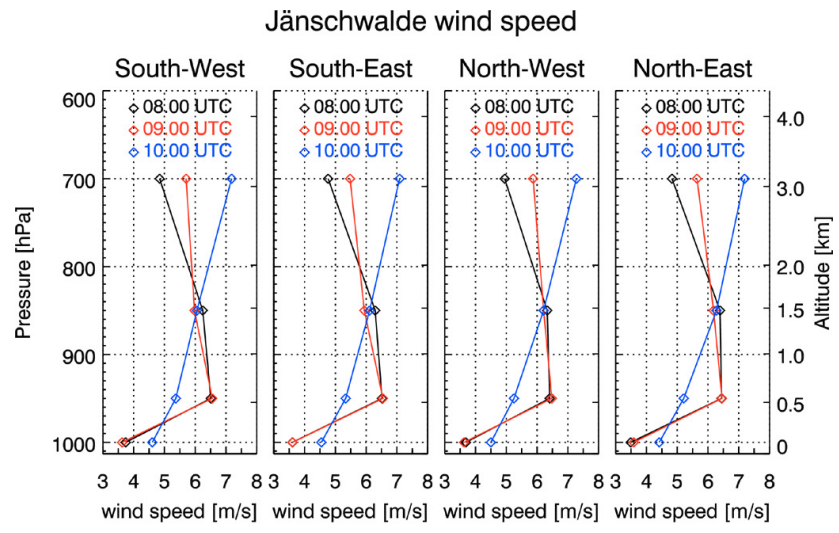

Schwarze Pumpe wind speed

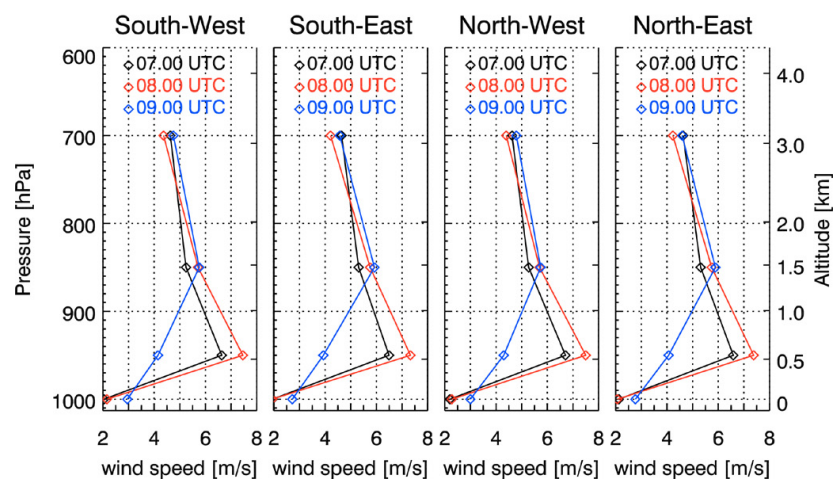

Fig. 5. Figure of wind speeds at the sites of the four nearest neighbours of the power plants Jänschwalde and Schwarze Pumpe according to the COSMO-DE model as used for the inversion process.

the solid black lines (Fig. 8 and 9). The black line shows the result of the measurement always using the nearest neighbour to a point on the line. Statistical errors are shown in grey. The results of the simulation based on the Gaussian plume model is shown in red. A good agreement between model and data can be achieved. However, the peak values in vicinity of the power plant cannot be reproduced whereas far from the power plant, the model generally underestimates the emissions. This may be connected to a non-constant stability parameter e.g. due to cooling of the flue gas. Despite the nonstationary wind conditions in case of Schwarze Pumpe, the model seems to fit the data very well.

The solid black lines in Fig. 3 downwind of the power plant stacks also indicate the boundaries chosen for the Gaussian integral approach. The upwind boundaries have not been used for the inversion (see Sect. 4.3) and are for visual purposes only.

The result of the inversions are given in Table 10. The plume model inversion results for Jänschwalde and Schwarze Pumpe are in good agreement with the emission rate reported by the power plant operator $(+8.7 \%$ and $-9.0 \%)$. For Schwarze Pumpe, the change in wind conditions leading to 


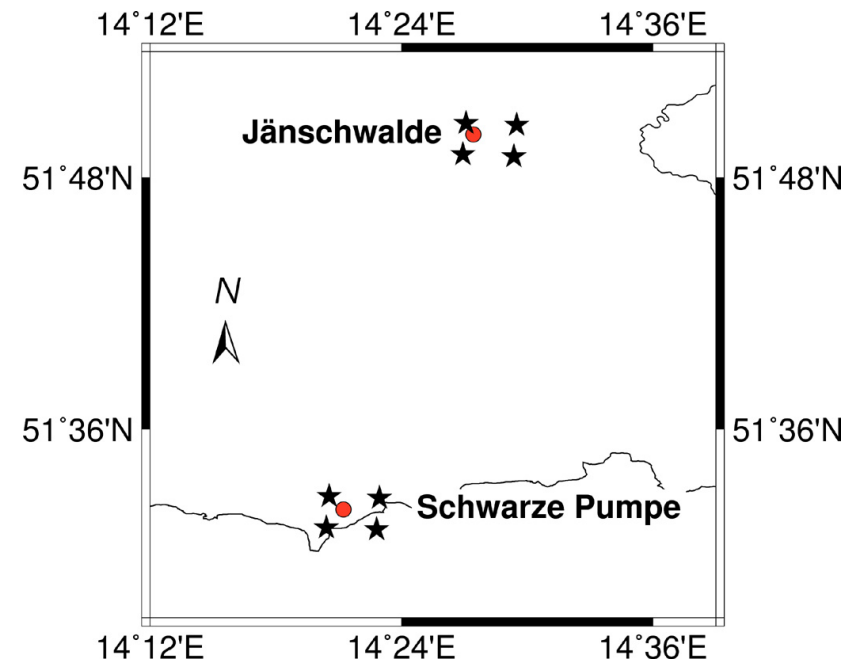

Fig. 6. Map showing the four nearest neighbours (black stars) of the power plants Jänschwalde and Schwarze Pumpe (red circle). Each of the power plants has a South-West, South-East, North-West and a North-East nearest neighbour according to the COSMO-DE data grid. The distance between both power plants is about $35 \mathrm{~km}$. Note that the map is not equidistant in North-South and East-West direction.

an unpredictable distribution of the plume and violating the quasi stationary conditions is partly compensated by fitting the stability parameter, which takes into account the plume broadening. For both power plants, the retrieved stability parameter is rather large indicating a distribution corresponding to very unstable conditions. Note that the reported emissions based on emission factors are not free of error either. However, thorough analysis of uncertainties on emission factors and hence the computed emissions are not available (compare also Sect. 1). The statistical errors based on the optimal estimation inversion are $7.0 \%$ and $12.4 \%$ for Jänschwalde and Schwarze Pumpe, respectively, and are based mainly on statistical measurement error and number of observations.

The statistical measurement error used for the plume inversion has been determined from the standard deviation given in Gerilowski et al. (2011) for the $\mathrm{CO}_{2}$ profile scaling factor ratios $\sigma_{\text {prof }}=1.74 \%$. Assuming an increase below the aircraft only, i.e. using the conversion factor for subcolumn retrieval for the present configuration $(k=0.475)$, this results in a standard deviation of $\sigma=0.83 \%$.

For the Gaussian integral, the results are about $0.2 \%$ and $9.9 \%$ below the reported emissions for Jänschwalde and Schwarze Pumpe, respectively, and hence in good agreement. These results assume that there is no systematic error on the inversion result due to the flight track. This assumption is valid for the Gaussian plume model fit but may depend strongly on the flight track pattern for the integral method (see Sect. 4.7.2).

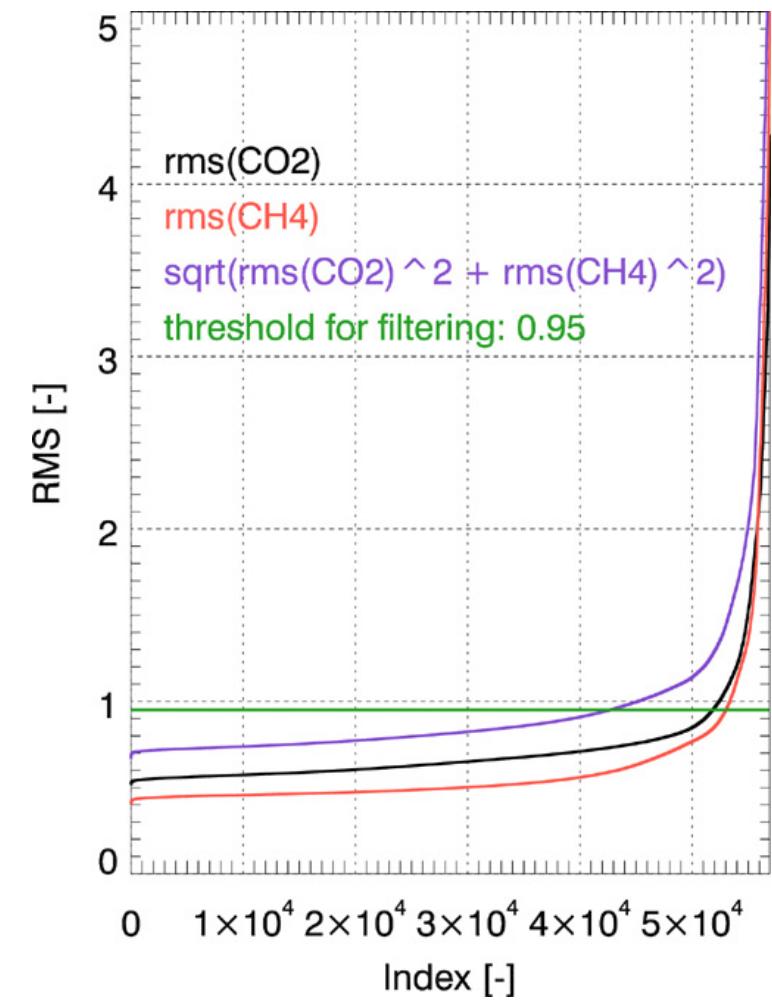

Fig. 7. Root mean square (rms) of the difference between fit and model for the dataset used for the inversion ordered by value. The green vertical line shows the filter threshold which was set to 0.95 for the analysis.

\subsection{Discussion of inversion errors}

\subsubsection{Wind and stability}

One of the largest uncertainties on the inversion results is caused by the uncertainty of the wind speed. Since wind speed is entering linearly into Eq. (13) the relative error directly translates into a relative error for the inversion. For the morning of 26 July 2007 and the air layers of interest, the data of the COSMO-DE model has a root mean square error (rmse) of about $0.9 \mathrm{~m} \mathrm{~s}^{-1}$ compared to wind profiler data from the Lindenberg Observatory (Berlin) and virtually no bias. The accuracy of the wind profilers used for the comparison can be assumed to be about $\sim 0.4 \mathrm{~m} \mathrm{~s}^{-1}$ (R. Leinweber, DWD, Lindenberg Observatory, personal communication, February 2011).

Also the uncertainty of the wind direction imposes an error on the inversion. For the wind direction, the rmse of the COSMO-DE model data for the according date and time is about $11^{\circ}$ with a bias of $-9^{\circ}$. The wind profilers have an accuracy of about $\sim 5^{\circ}$ (R. Leinweber, DWD, Lindenberg Observatory, personal communication, February 2011). However, the wind direction can also be derived from the measured data directly. 

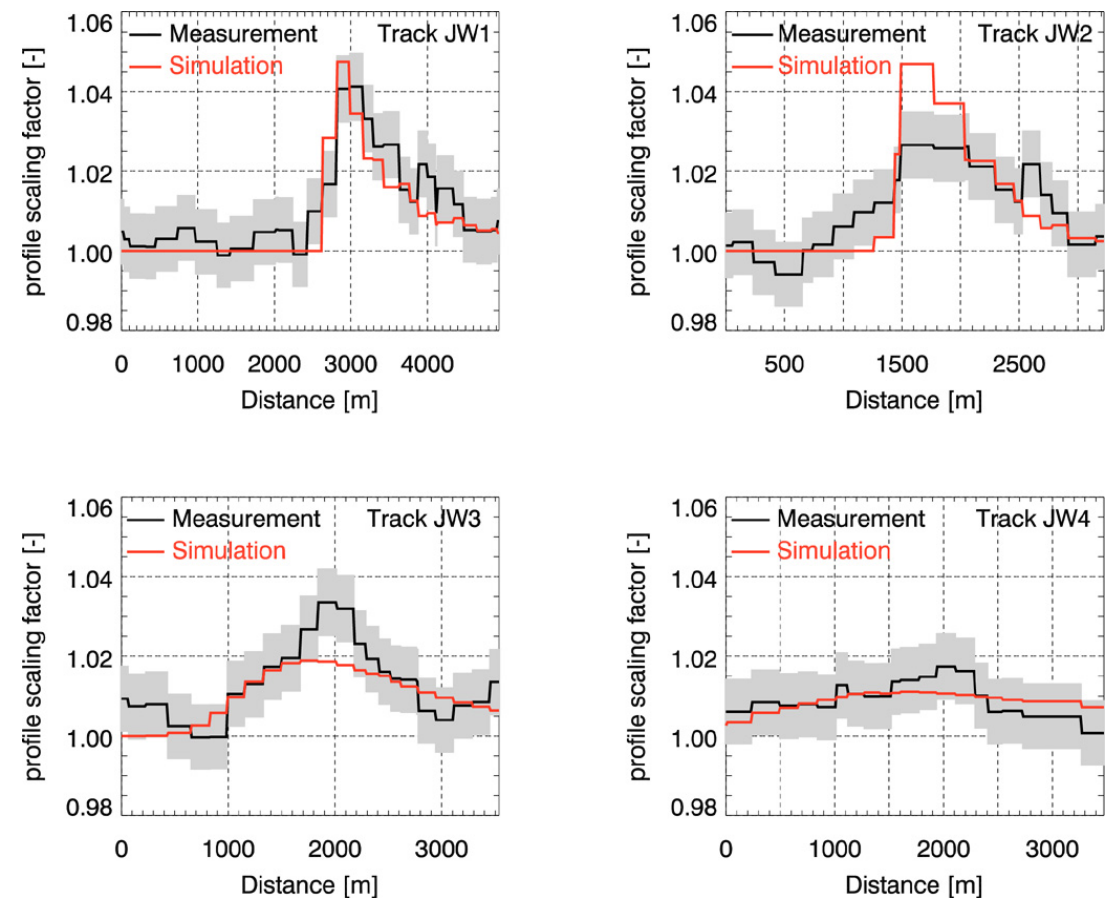

Fig. 8. The figure shows model data (red) computed from the inversion result for the Gaussian plume model and measurements (black) in case of Jänschwalde power plant along horizontal cross sections through the $\mathrm{CO}_{2}$ plume. Statistical errors are shown in grey. For the track numbers compare Fig. 3.
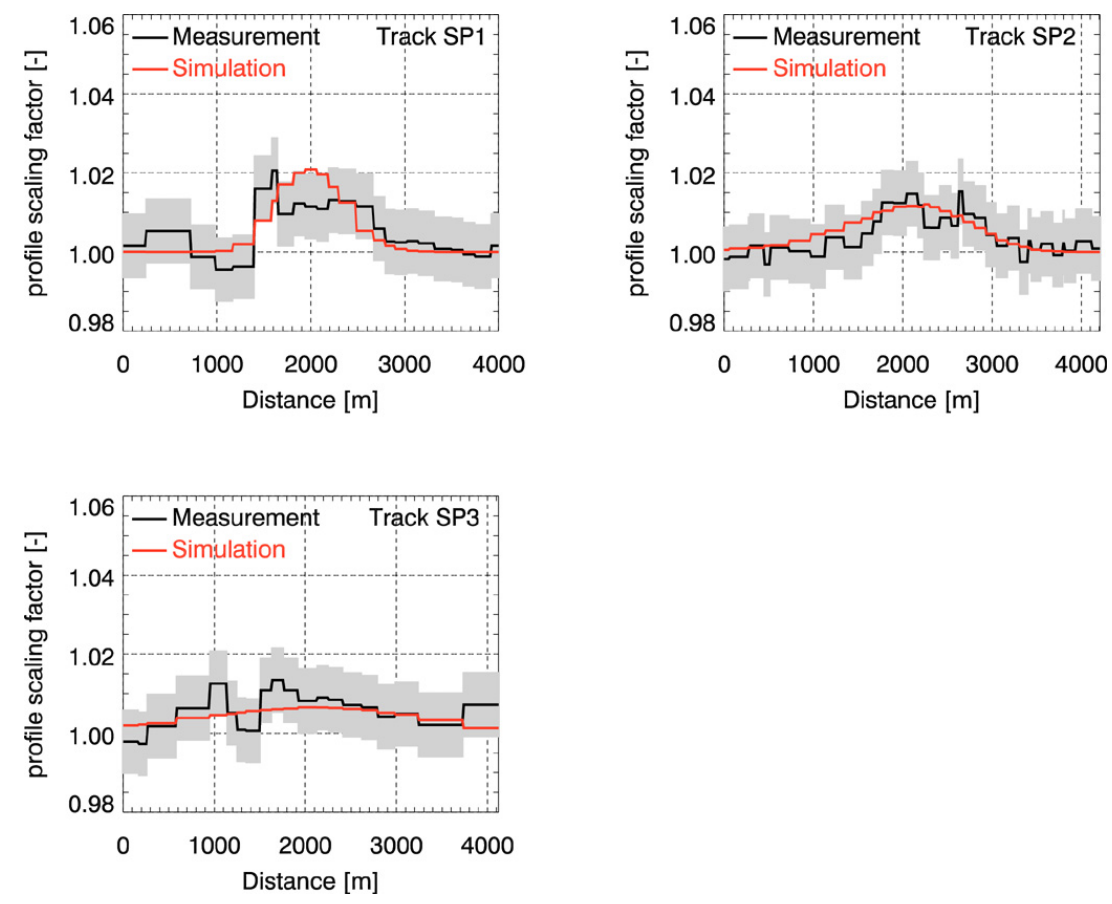

Fig. 9. The figure shows model data (red) computed from the Gaussian plume inversion and measurements (black) in case of Schwarze Pumpe power plant along horizontal cross sections through the $\mathrm{CO}_{2}$ plume. Statistical errors are shown in grey. For the track numbers compare Fig. 3. 
Table 11. Systematic errors in emission rate and stability parameter $a$ caused by choosing a wrong wind direction for plume model and Gaussian integral inversion of simulations of the Jänschwalde and Schwarze Pumpe power plant overflight. Default wind direction for the simulated data was $228^{\circ}$ (Jänschwalde) and $210^{\circ}$ (Schwarze Pumpe), default stabilities assumed for the simulation same as the retrieved stabilities for Jänschwalde and Schwarze Pumpe in Table 10. The results for the integral inversion have already been corrected for the systematic error due to the flight pattern.

\begin{tabular}{|c|c|c|c|c|c|c|}
\hline \multirow{3}{*}{$\begin{array}{c}\Delta \text { wind direction } \\
\left.{ }^{\circ}\right]\end{array}$} & \multicolumn{3}{|c|}{ Jänschwalde } & \multicolumn{3}{|c|}{ Schwarze Pumpe } \\
\hline & \multicolumn{2}{|c|}{$\Delta$ emission rate $[\%]$} & \multirow{2}{*}{$\begin{array}{c}\Delta \text { stability } \\
\text { retrieved [\%] }\end{array}$} & \multicolumn{2}{|c|}{$\Delta$ emission rate $[\%]$} & \multirow{2}{*}{$\begin{array}{c}\Delta \text { stability } \\
\text { retrieved [\%] }\end{array}$} \\
\hline & Plume & Integral & & Plume & Integral & \\
\hline 0 & +0.0 & +0.0 & +0.0 & +0.0 & +0.0 & +0.0 \\
\hline+1 & +0.5 & +1.7 & +1.2 & +0.3 & -0.3 & +0.1 \\
\hline-1 & -0.4 & -1.8 & -1.1 & -0.2 & +0.3 & +0.0 \\
\hline+2 & +3.2 & +3.4 & +5.0 & +0.0 & -0.7 & +0.6 \\
\hline-2 & -2.7 & -3.6 & -2.4 & -0.6 & +0.6 & +0.3 \\
\hline+3 & +3.1 & +5.1 & +6.9 & -0.8 & -1.1 & +0.3 \\
\hline-3 & -1.9 & -5.4 & -0.3 & -0.2 & +0.9 & +0.9 \\
\hline+5 & +5.3 & +8.3 & +10.9 & -1.8 & -2.0 & +1.3 \\
\hline-5 & -4.5 & -9.1 & -0.6 & -1.7 & +1.3 & +1.6 \\
\hline+10 & +1.7 & +15.9 & +15.8 & -4.7 & -4.8 & +8.0 \\
\hline-10 & -6.1 & -18.9 & +16.8 & -3.7 & +1.8 & +7.5 \\
\hline
\end{tabular}

A special simulation set up was chosen to assess the influence of the wind direction on the inversion result in the special case of the measurements over Jänschwalde and Schwarze Pumpe power plant presented here. To keep the simulation as realistic as possible, the inversion uses simulated measurements only at points where the MAMAP sensor actually recorded high quality data during the overflight. Simulated data was produced assuming a wind direction of $228^{\circ}$ (Jänschwalde) and $210^{\circ}$ (Schwarze Pumpe), whereas the inversion was run assuming several different wind directions. The results are summarised in Table 11. It can be seen that for the present flight pattern, the inversion bias is not symmetric as regards the change of wind direction. For example, in case of Jänschwalde errors in wind direction of $\pm 5^{\circ}$ can result in an inversion error of $+5.3 \%$ and $-4.5 \%$ for the plume fit, and $+8.3 \%$ and $-9.1 \%$ for the integral approach, respectively. For Schwarze Pumpe, the errors are $-1.8 \%$ and $-1.7 \%$ for the plume inversion, and $-2.0 \%$ and $+1.3 \%$ for the integral method. In general, the denser the measurements are in quasi-stationary conditions, the more precisely the wind direction can be determined due to a characteristic mismatch of data and model fit (compare Bovensmann et al., 2010).

\subsubsection{Flight pattern and Gaussian integral}

In theory, the flight pattern does not matter for the Gaussian plume inversion when computing the emission rate. It will only reduce the uncertainty on the final result. This has also been confirmed by inversion of simulated data. For the Gaussian integral, however, the flight pattern is of crucial importance. When simulating a plume and applying the flight patterns actually flown over Jänschwalde and Schwarze Pumpe for the inversion, the Gaussian integral does not give the source emission rate. From Fig. 3, it can already be seen, that flight paths for Jänschwalde are rather unfortunate for applying the integral method. Not only is one path of the aircraft going exactly above the power plant but also the track to the very east has not been long enough to cover the full horizontal plume extent. Under this condition, the assumption that there is no $\mathrm{CO}_{2}$ transport perpendicular to the wind direction is not reasonable. This is also confirmed by the simulation which yields an emission rate of about $82.3 \%$ of the true emission rate. This is a systematic error that will also appear in the inversion of the real measurements. Hence the result may have to be corrected for this flight track error by multiplying the final result with a factor of $\sim 1.22$.

For Schwarze Pumpe, the flight tracks are more suitable, since they have been long enough at appropriate distances to the power plant. Here, the simulation result is at about $96.9 \%$ compared to the true emission rate, showing that there is almost no systematic error resulting from the choice of flight pattern in this case.

It is of importance for future measurements to apply appropriate flight patterns, like for example the one at Schwarze Pumpe. More sophisticated interpolation methods compared to the nearest neighbour approach (which was used for this study) may also lead to improved inversion results in case of unfortunate flight patterns. 


\subsubsection{Aerosol sensitivity for the inversion at Jänschwalde power plant}

To assess the influence of aerosols on the inversion results, model simulations adapted to MAMAP measurements over the power plant Jänschwalde were performed, where atmospheric conditions were more favourable (i.e. more stable) compared to Schwarze Pumpe power plant.

The estimate for $\mathrm{PM}_{10}$ release from power plants of $1 \mathrm{~g} \mathrm{PM}_{10} \mathrm{~kW} \mathrm{~h}^{-1}$ given in Bovensmann et al. (2010, and references therein) is too conservative for modern lignite coal-fired power plants like the ones under consideration in this study. The US National Renewable Energy Laboratory (NREL) states emission factors of $41.6 \mathrm{mg} \mathrm{PM}_{10} \mathrm{kWh}^{-1}$ for $\mathrm{PM}_{10}$ and $0.714 \mathrm{~kg} \mathrm{CO}_{2} \mathrm{kWh}^{-1}$ for carbon dioxide averaged over all electric power generation facilities including gas and nuclear power plants in the US (Deru and Torcellini, 2006, revised 2007). For the state of North Dakota which produces $91.8 \%$ of its electrical energy from lignite coal, the average emission factor is $138 \mathrm{mg} \mathrm{PM}_{10} \mathrm{~kW} \mathrm{~h}^{-1}$ and $1.18 \mathrm{~kg} \mathrm{CO}_{2} \mathrm{kWh}^{-1}$.

Hence, there is a release of about $120 \mathrm{mg} \mathrm{PM}_{10} \mathrm{~kg}^{-1} \mathrm{CO}_{2}$. Assuming a perfect correlation between $\mathrm{PM}_{10}$ and $\mathrm{CO}_{2}$ and additionally taking into account that the $\mathrm{CO}_{2}$ background column is about $6 \mathrm{~kg} \mathrm{~m}^{-2}$, this results in an increase of roughly $\sim 10 \mathrm{mg} \mathrm{PM}_{10} \mathrm{~m}^{-2}$ per $1 \%$ columnar $\mathrm{CO}_{2}$ increase.

By using mass extinction coefficients as used by Trier et al. (1997) $\left(4.93 \mathrm{~m}^{2} \mathrm{~g}^{-1}\right.$ at $550 \mathrm{~nm}$ for urban aerosol $\left.\mathrm{PM}_{2.5}\right)$ and integrating over the full height or alternatively applying the equation of Raut and Chazette (2009) relating urban $\mathrm{PM}_{10}$ concentrations to the extinction coefficient $\alpha_{\text {ext, } 355 \mathrm{~nm}}$ at $355 \mathrm{~nm}$ derived from LIDAR measurements $\left(\mathrm{PM}_{10}=\right.$ $0.217 \mathrm{~g} \mathrm{~m}^{-2} \times \alpha_{\text {ext }, 355 \mathrm{~nm}}$ ), an increase in AOT due to a $1 \%$ increase in $\mathrm{CO}_{2}$ of about 0.05 can be estimated.

To model the aerosol impact on the inversion result more realistically, both $\mathrm{CO}_{2}$ and the aerosol were distributed horizontally and in different height layers via a 3-dimensional Gaussian plume model depending on distance in wind and off-wind direction and height, with the origin at the stack locations at the corresponding emission heights. For each ground pixel, the according radiative transfer has been computed including aerosol load and its height distribution.

The results for the $\mathrm{CO}_{2}$ over $\mathrm{CH}_{4}$ ratios are shown in Fig. 10. The maximum error in a measurement pixel is about $0.03 \%$ occurring close to the power plant where aerosol load will be the largest. This, however, has only a minor effect on the plume inversion giving rise to a bias of $+0.4 \%$ on the emission rate after inversion. For the integral inversion, the bias is about $+0.3 \%$ compared to the inversion not accounting for a particular aerosol distribution. Hence, impact of aerosol scattering and absorption for coal-fired power plants equipped with modern filter mechanism is insignificant for the retrieval and the subsequent inversions applied here.

The power plants Jänschwalde and Schwarze Pumpe emit even less particulate matter than was assumed for

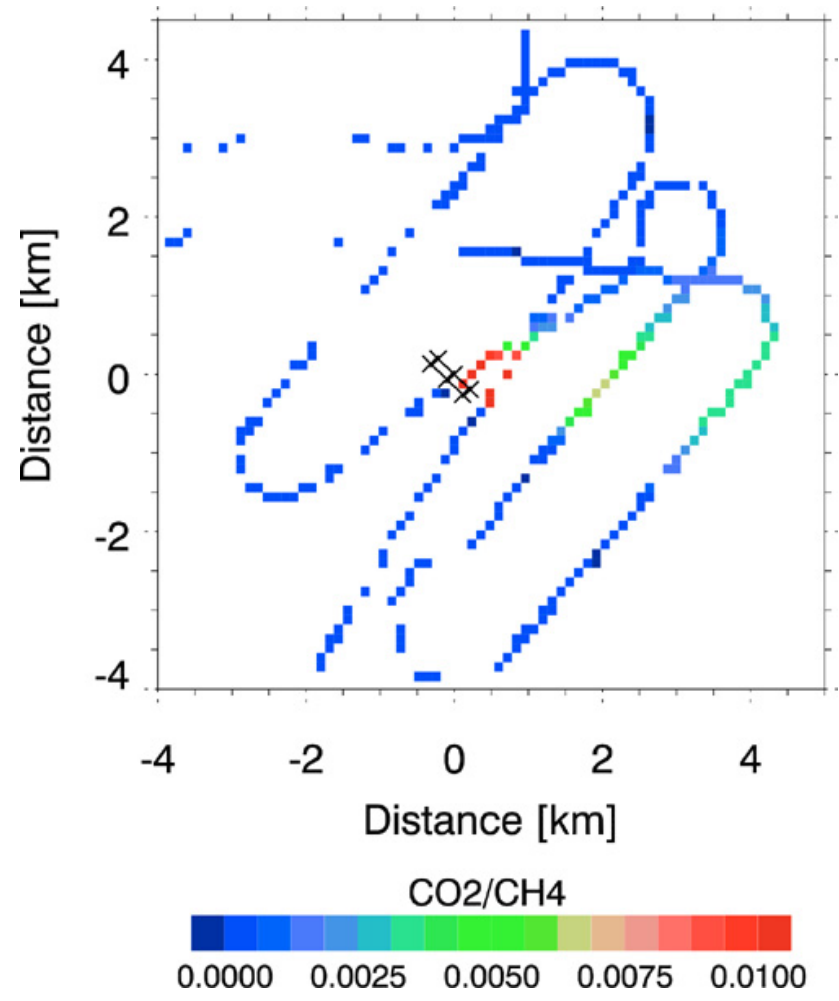

Fig. 10. Systematic biases due to aerosol alone at the example of Jänschwalde power plant. Maximum error in close vicinity to the power plant is about $0.03 \%$ relative to the background column. The overall plume model inversion is only biased by about $+0.4 \%$ of the true emission rate.

this sensitivity study. The actual emission for both power plants is less than $20 \mathrm{mgdust}_{\mathrm{kW} \mathrm{h}}^{-1}$ and about $17 \mathrm{mg} \mathrm{PM}_{10} \mathrm{kWh}^{-1}$. For comparison, the specific $\mathrm{CO}_{2}$ emissions of Jänschwalde are $1.15 \mathrm{~kg} \mathrm{CO}_{2} \mathrm{~kW} \mathrm{~h}^{-1}$ and for Schwarze Pumpe $1.0 \mathrm{~kg} \mathrm{CO}_{2} \mathrm{~kW} \mathrm{~h}^{-1}$.

\subsubsection{Sensitivity to the conversion factor $k$ for Jänschwalde power plant}

The conversion factor $k$ accommodating for a $\mathrm{CO}_{2}$ increase below the aircraft (Table 1) depends not only on the aircraft altitude but also on the distribution of emitted $\mathrm{CO}_{2}$ below the aircraft, because the averaging kernels are not constant with height. The distribution and plume height, however, are generally not well known, so that the conversion factor is only used as an average value for the subcolumn. Figure 11 shows the systematic errors resulting from using the average conversion factor on a Gaussian distributed $\mathrm{CO}_{2}$ plume in case of Jänschwalde power plant. However, the highest deviation of the retrieved enhancement from the true enhancement is only about $0.06 \%$ relative to background occurring close to the power plant, leading to a bias on the plume inversion of $+1.3 \%$ of the estimated emission rate. For the integral inversion, the bias is $+0.9 \%$ relative to the result with an 


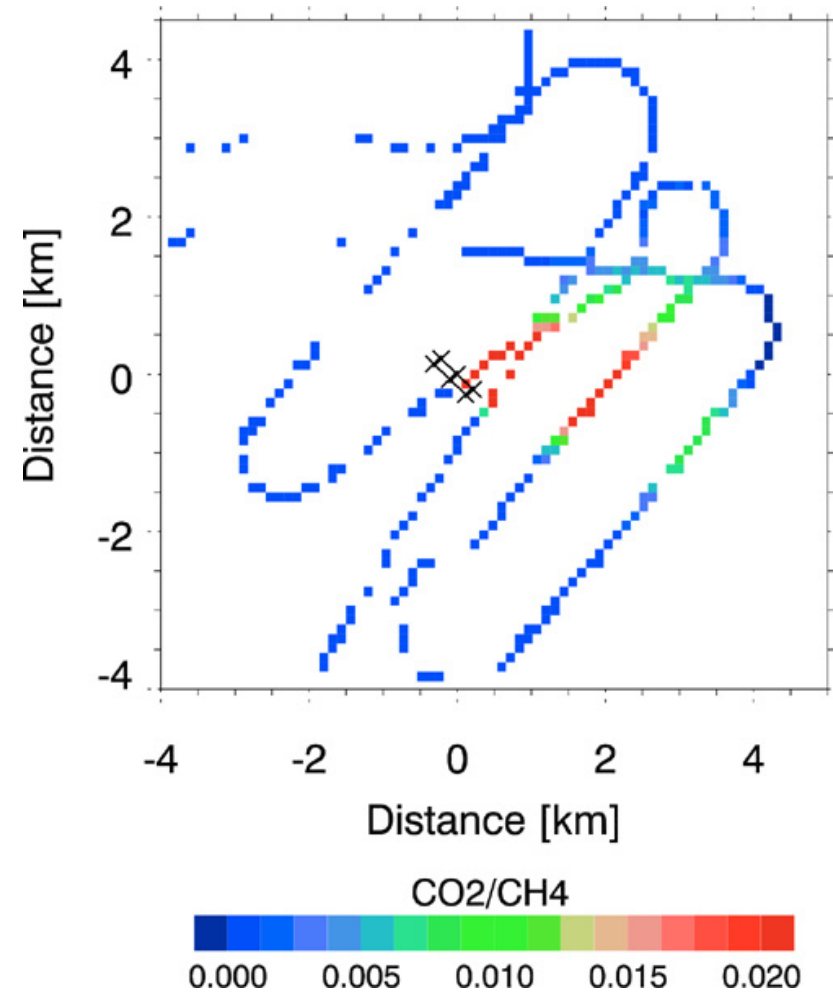

Fig. 11. Propagated error on the retrieval result due to error on the conversion factor, because of insufficient knowledge of the plume height and vertical distribution. Highest deviation from the true value is about $0.06 \%$ relative to the background column. The error in the conversion factor estimation leads to a bias of $+1.33 \%$ of the true emission rate using the plume inversion method.

adapted conversion factor $k$ depending on the vertical $\mathrm{CO}_{2}$ distribution.

\subsubsection{Summary of inversion uncertainties}

Generally, the inversion results are in good agreement with the reported values (Table 10). Table 12 summarises typical error sources and resulting uncertainties for the inverted emission rates of the two power plants. The errors are clearly dominated by uncertainties on wind information. The standard deviation of the model wind speed $\left(0.9 \mathrm{~m} \mathrm{~s}^{-1}\right)$ for the respective day and time of day are used for the uncertainty on the wind data in this case. In future campaigns, on-site wind information will help to validate the model and to better assess the according error.

Wind directions were derived empirically from the data but due to violation of the stationarity assumption for the Gaussian plume model in case of Schwarze Pumpe, results of the inversion can be expected to have a larger bias. The correction applied by differential rotation of the data and retrieval of the stability parameter $a$ can only partly compensate for that. To account for this additional issue the error on wind direction is assumed higher for Schwarze Pumpe $\left( \pm 10^{\circ}\right)$ than for Jänschwalde $\left( \pm 5^{\circ}\right)$.

The errors introduced by additional aerosol load due to emissions from the power plant and by variations of the conversion factor $k$ are rather small compared to the other error sources. The flight pattern imposes an error for the Gaussian integral method, but can be mitigated by performing appropriate flight patterns during measurements.

The uncertainty on the reported emission rate has been disregarded for this comparison so far. The emission factor estimate can be assumed to have a precision of about $1.5 \%$ (in accordance with the EU guidelines, compare Sect. 1), but the accuracy may be significantly worse (Evans et al., 2009).

\section{Summary and conclusions}

MAMAP is an airborne optical grating spectrometer instrument for passive remote sensing of column amounts of the greenhouse gases $\mathrm{CO}_{2}$ and $\mathrm{CH}_{4}$ with a precision of $\lesssim 1 \%$ (Gerilowski et al., 2011).

The $X \mathrm{XO}_{2}$ derived from ratios of $\mathrm{CO}_{2}$ and $\mathrm{CH}_{4}$ retrieved with the modified WFM-DOAS algorithm have been shown to be robust against changes of atmospheric parameters like aerosol content, cirrus clouds, solar zenith angle, etc. Biases may be large in the single gas columns but largely cancel for the ratios, leading to a significantly enhanced data quality.

A test flight has been performed over the two power plants Jänschwalde (ca. 27.4 $\mathrm{MtCO}_{2} \mathrm{yr}^{-1}$ ) and Schwarze Pumpe (ca. $11.9 \mathrm{MtCO}_{2} \mathrm{yr}^{-1}$ ) on 26 July 2007 (Sect. 4.1). The retrieved columns clearly show the $\mathrm{CO}_{2}$ plume (Figs. 12 and 13). However, a more quantitative description of the power plant emission rates is of interest, as it is also for other strong point sources.

Two inversion approaches to obtain these emission rates have been applied: The Gaussian plume inversion (Sect. 4.2) and the Gaussian integral inversion method (Sect. 4.3). One of the most crucial input parameters for both inversion models is the wind speed. Errors in wind speed enter linearly into the equations for both methods (Eqs. 18 and 25) and hence, so do the relative errors on the wind speed. Another very important factor is the flight pattern performed over the point source to be assessed (Sect. 4.7.2). Especially for the Gaussian integral method, systematic errors can be significant (e.g. about $17.7 \%$ in the case of Jänschwalde power plant) but they can be almost completely avoided if an appropriate flight pattern is performed (error only $3.1 \%$ in case of Schwarze Pumpe). In addition, recent measurements with the improved MAMAP sensor indicate a drastically improved instrumental precision which will reduce the influence of patchy data on the nearest neighbour approach in the future. In the case of the Gaussian plume model, the flight pattern is not of that importance. It mainly reduces the statistical error. However, it is of advantage to densely sample the plume centre with highest values above background and 

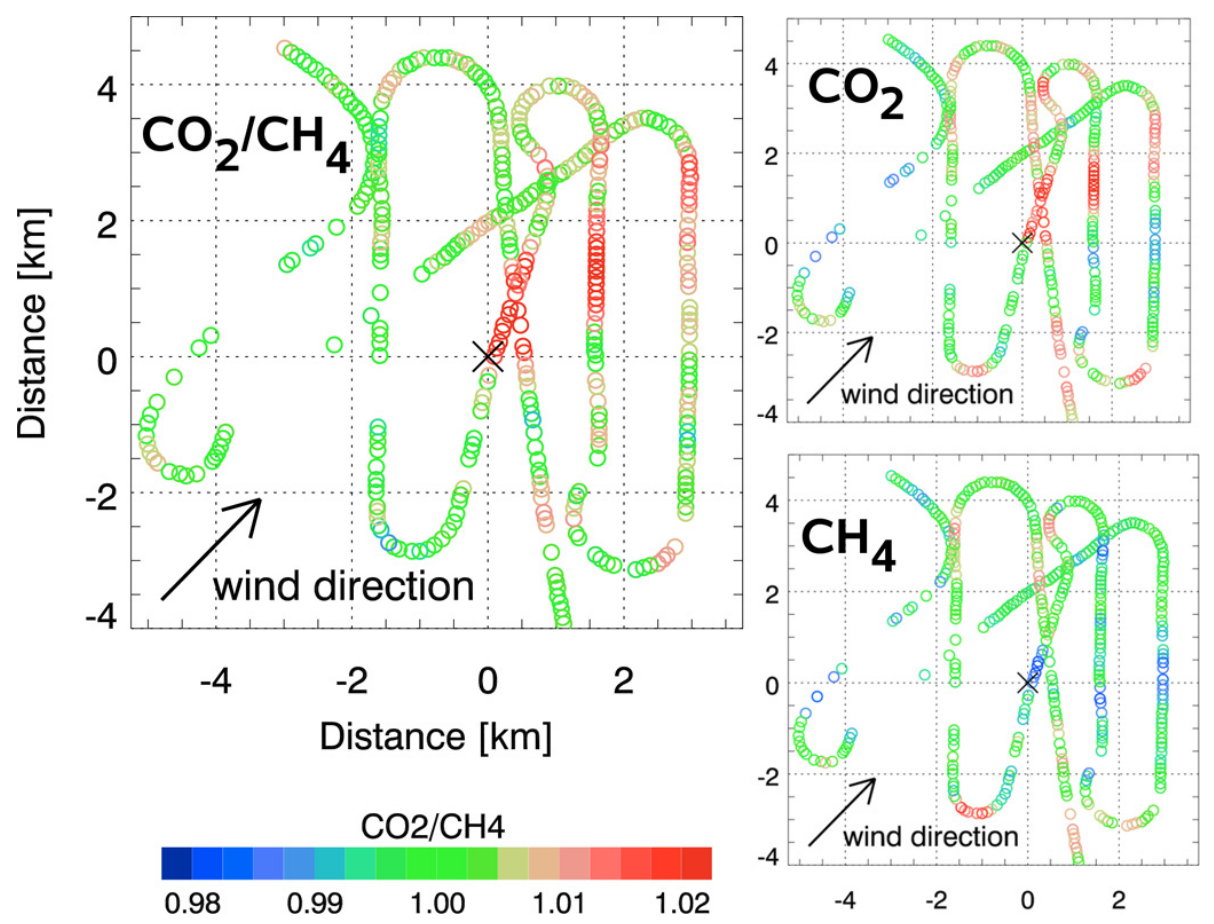

Fig. 12. MAMAP data from Jänschwalde power plant. The left picture shows the profile scaling factor ratio $\mathrm{CO}_{2} / \mathrm{CH}_{4}\left(X \mathrm{CO}_{2}\right)$. The upper right picture shows that the $\mathrm{CO}_{2}$ emissions can already be detected by the $\mathrm{CO}_{2}$ measurements and are not features introduced by possible errors in the $\mathrm{CH}_{4}$ measurements (lower right). The single gas pictures (right) also show errors that occur for both measurements e.g. when the aircraft is turning. All data has been normalised by the global mean of the complete flight and smoothed by a 3 point moving average. (Note that data on figures to the right do not represent dry columns and have been additionally offset corrected for displaying reasons. They do not have the same profile scaling factor scale as the ratios shown on the left.)

Table 12. Overall uncertainty on the final emission rate estimates for the power plants Jänschwalde (JW) and Schwarze Pumpe (SP). Note that Schwarze Pumpe has a higher assumed uncertainty on the wind direction $\left( \pm 10^{\circ}\right)$ due to nonstationary conditions.

\begin{tabular}{|c|c|c|c|c|}
\hline \multirow[b]{3}{*}{ Parameter } & \multicolumn{4}{|c|}{ Uncertainty on emission rate [\%] } \\
\hline & \multicolumn{2}{|c|}{ Plume inversion } & \multicolumn{2}{|c|}{ Gaussian integral } \\
\hline & JW & SP & JW & SP \\
\hline Statistical error & 7.0 & 12.4 & $*$ & $*$ \\
\hline Wind speed $\left( \pm 0.9 \mathrm{~m} \mathrm{~s}^{-1}\right)$ & 20.0 & 27.3 & 20.0 & 27.3 \\
\hline Wind direction $\left( \pm 5^{\circ}\right.$ resp. $\left.\pm 10^{\circ}\right)$ & 5.3 & 4.7 & 9.1 & 4.8 \\
\hline Aerosol & 0.4 & $*$ & 0.3 & $*$ \\
\hline Conversion factor $k$ & 1.3 & $*$ & 0.9 & $*$ \\
\hline Flight pattern (can be accounted for) & - & - & -17.7 & -3.1 \\
\hline
\end{tabular}

* according values not determined; - parameter not important for method

hence, also highest signal to noise ratio. Further errors e.g. from the choice of wind direction etc. have been analysed.

The results - not corrected for any systematic errors - of the inversions can be found in Table 10. Relative to the reported values, the emission rates of Jänschwalde are overestimated by $8.3 \%$ (plume model) and underestimated by $0.2 \%$ (Gaussian integral). For Schwarze Pumpe, the emission rates have been underestimated by $9.0 \%$ (Gaussian plume) respectively by about $9.9 \%$ (Gaussian integral). The results show that a rather accurate assessment of the emission rates can be obtained. In the case of Schwarze Pumpe, unfortunate (i.e. non-stationary) wind conditions did complicate the inversion process. Main error sources are summarised in Table 12, being dominated by the uncertainty on wind information. In an extensive simulation, the error caused by aerosol scattering and absorption and the error on the conversion factor have turned out to be not significant. 

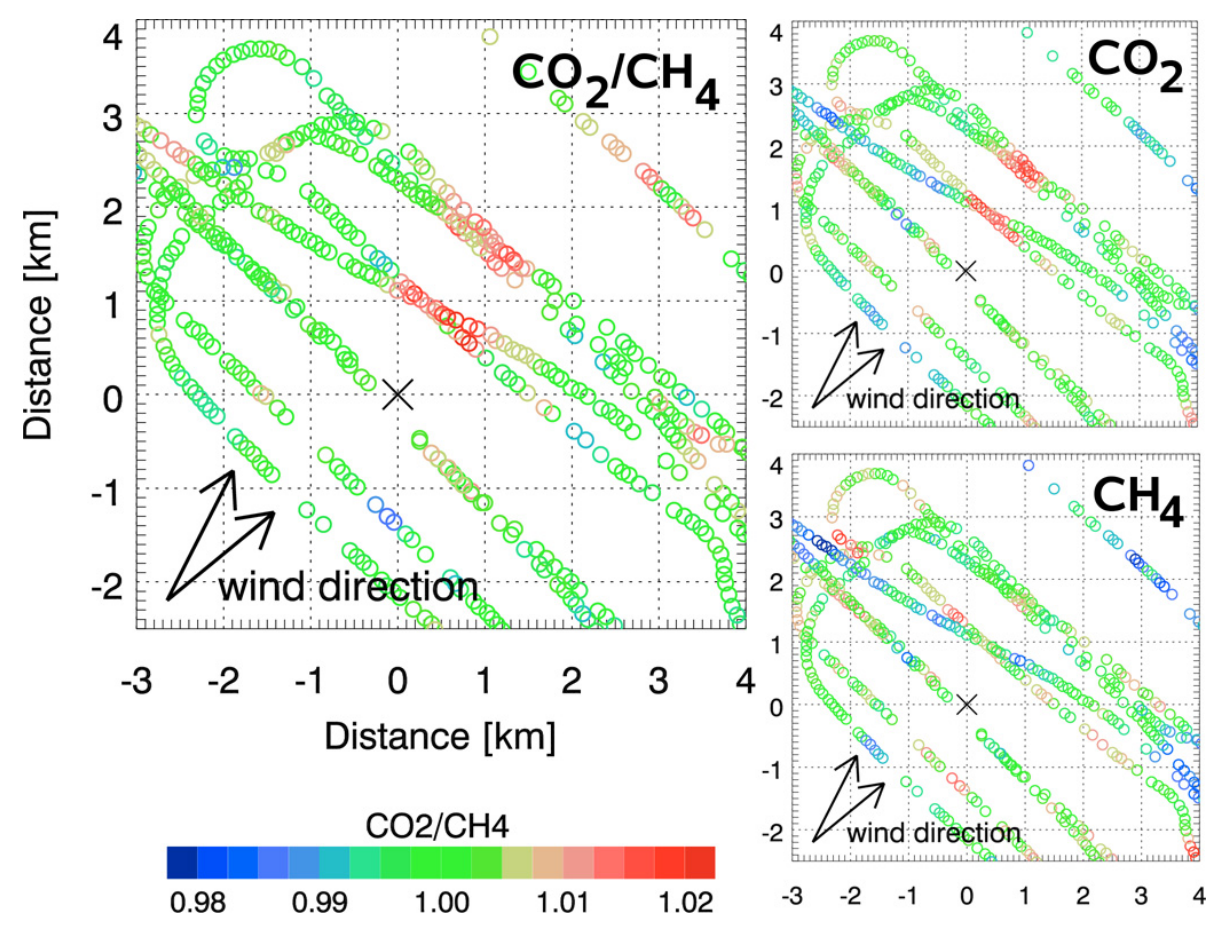

Fig. 13. Same as Fig. 12 but for Schwarze Pumpe power plant. Again the power plant emission plume is already clearly visible in the $\mathrm{CO}_{2}$ measurement (i.e. before the ratio $\mathrm{CO}_{2} / \mathrm{CH}_{4}$ is computed).

For the analysis shown here, the wind data of the routine analysis of the numerical weather prediction model COSMO-DE of the German Weather Service (DWD) has been used. Although this model has a horizontal resolution of $2.8 \mathrm{~km}$ and an hourly output, wind information with higher resolution in space and time is desirable to increase the accuracy of the final results. A first improvement will be to utilise the full vertical resolution of COSMO-DE which was not available for this study. The MAMAP sensor in combination with a wind LIDAR or radar with high accuracies of $\leq 1 \mathrm{~m} \mathrm{~s}^{-1}$ (wind speed) and $10^{\circ}$ (wind direction), temporal resolution of about $15 \mathrm{~min}$ and a vertical resolution of ca. $100 \mathrm{~m}$ like the instrument presented for example by Norton et al. (2006) can significantly improve the inversion. Furthermore, it is also planned to use MAMAP with an in-situ analyser and a turbulence probe for further validation and better vertical (and horizontal) location of the plume.

In direct comparison, both inversion methods - the Gaussian plume inversion and the Gaussian integral method - are able to deliver accurate results. The Gaussian plume method requires more detailed knowledge of atmospheric conditions but it can incorporate all available data resulting in a reduced statistical uncertainty. In cases where atmospheric parameters are not well known, the Gaussian integral method may be of advantage because of its independence of the atmospheric stability and the rather low sensitivity on variations of wind direction. On the other hand it can be strongly biased by a few outliers.
The inversion methods presented here at the example of two strong $\mathrm{CO}_{2}$ point sources can also be accordingly applied for localised $\mathrm{CH}_{4}$ sources. With respect to mass, the sensitivity of MAMAP to $\mathrm{CH}_{4}$ is about 500 times higher than for $\mathrm{CO}_{2}$ because of the lower $\mathrm{CH}_{4}$ background concentrations (measurements are relative to background), lower molecular weight of $\mathrm{CH}_{4}$ and taking into account conversion factors $k$ for an aircraft altitude of $1.25 \mathrm{~km}$, an albedo of 0.18 and a background aerosol scenario (compare Table 1). For comparison, equivalent $\mathrm{CH}_{4}$ emissions to obtain a similar $\mathrm{CH}_{4}$ MAMAP signal as the emission rates of Schwarze Pumpe and Jänschwalde do for $\mathrm{CO}_{2}$, would be in the order of $\sim 24 \mathrm{ktCH}_{4} \mathrm{yr}^{-1}$ and $\sim 55 \mathrm{kt} \mathrm{CH}_{4} \mathrm{yr}^{-1}$, respectively. A potential MAMAP target of this order of magnitude could be, for example, the offshore Mobil Oil North Sea Blowout $\left(\sim 23 \mathrm{ktCH}_{4} \mathrm{yr}^{-1}\right.$, with very high degree of uncertainty, Deutscher Bundestag - 17. Wahlperiode, 2010), when operating in solar glint. Of course, detection and quantification of much less intense $\mathrm{CH}_{4}$ (and $\mathrm{CO}_{2}$ ) sources are feasible.

To conclude, it has been shown that MAMAP has the ability to quantify point source emission rates from power plants. Even with the simple methods presented here, the accuracy of the inversion results is already in the order of the uncertainties as presented by Ackerman and Sundquist (2008). Other $\mathrm{CO}_{2}$ point sources like cement and steel factories, as well as $\mathrm{CH}_{4}$ localised emissions e.g. from landfills and fossil fuel production and distribution, can also be quantified with the methods presented here. Not only can MAMAP deliver 
significant information on greenhouse gas emissions from localised sources but it may also serve to validate and complement satellite measurements of current and future satellite missions, e.g. like the proposed greenhouse gas satellite mission CarbonSat (Bovensmann et al., 2010).

Acknowledgements. This work and MAMAP flights and ground operations were funded by the University and State of Bremen, Germany, by the Helmholtz Centre Potsdam, GFZ German Research Centre for Geosciences and by the Institute for Space Science (ISS), Free University (FU), Berlin, Germany. Preprocessed wind data from the German Weather Service (DWD) COSMO-DE model and information on wind profiler radars were provided by R. Leinweber, Free University, Berlin, Germany (now at German Weather Service (DWD), Lindenberg Observatory). The authors would like to thank O. Schneising and J. Heymann for helpful comments on this work. The solar spectrum has been obtained from NSO/Kitt Peak (http://solarnews.nso.edu) and was produced cooperatively by NSF/NOAO, NASA/GSFC and NOAA/SEL. We would like to thank F.-M. Bréon and another anonymous referee for their comments on the discussion version of this manuscript which resulted in a significantly improved publication.

Edited by: A. J. M. Piters

\section{References}

Ackerman, K. V. and Sundquist, E. T.: Comparison of Two U.S. Power-Plant Carbon Dioxide Emissions Data Sets, Environ. Sci. Technol., 42, 5688-5693, doi:10.1021/es800221q, 2008.

Babilotte, A., Lagier, T., Fiani, E., and Taramini, V.: Fugitive Methane Emissions from Landfills: Field Comparison of Five Methods on a French Landfill, J. Environ. Eng., 136, 777-784, doi:10.1061/(ASCE)EE.1943-7870.0000260, 2010.

Beychok, M. R.: Fundamentals of Stack Gas Dispersion, Milton R. Beychok, 4th edn., 2005.

Börjesson, G., Danielsson, Å., and Svennson, B. H.: Methane Fluxes from a Swedish Landfill Determined by Geostatistical Treatment of Static Chamber Measurements, Environ. Sci. Technol., 34, 4044-4050, 2000.

Bovensmann, H., Burrows, J., Buchwitz, M., Frerick, J., Noël, S., and Rozanov, V.: SCIAMACHY: Mission Objectives and Measurement Modes, J. Atmos. Sci., 56, 127-150, 1999.

Bovensmann, H., Buchwitz, M., Burrows, J. P., Reuter, M., Krings, T., Gerilowski, K., Schneising, O., Heymann, J., Tretner, A., and Erzinger, J.: A remote sensing technique for global monitoring of power plant $\mathrm{CO}_{2}$ emissions from space and related applications, Atmos. Meas. Tech., 3, 781-811, doi:10.5194/amt-3-781-2010, 2010.

Buchwitz, M., Rozanov, V. V., and Burrows, J. P.: A near-infrared optimized DOAS method for the fast global retrieval of atmospheric $\mathrm{CH}_{4}, \mathrm{CO}, \mathrm{CO}_{2}, \mathrm{H}_{2} \mathrm{O}$, and $\mathrm{N}_{2} \mathrm{O}$ total column amounts from SCIAMACHY Envisat-1 nadir radiances, J. Geophys. Res., 105, 15231-15245, 2000.

Buchwitz, M., de Beek, R., Burrows, J. P., Bovensmann, H., Warneke, T., Notholt, J., Meirink, J. F., Goede, A. P. H., Bergamaschi, P., Körner, S., Heimann, M., and Schulz, A.: Atmospheric methane and carbon dioxide from SCIAMACHY satellite data: initial comparison with chemistry and transport models, Atmos. Chem. Phys., 5, 941-962, doi:10.5194/acp-5-941-2005, 2005a.

Buchwitz, M., de Beek, R., Noël, S., Burrows, J. P., Bovensmann, H., Bremer, H., Bergamaschi, P., Körner, S., and Heimann, M.: Carbon monoxide, methane and carbon dioxide columns retrieved from SCIAMACHY by WFM-DOAS: year 2003 initial data set, Atmos. Chem. Phys., 5, 3313-3329, doi:10.5194/acp-53313-2005, 2005b.

Chambers, A. and Strosher, M.: DIAL Measurements of Fugitive Emissions from Natural Gas Plants and the Comparison with Emission Factor Estimates, 15th Annual Emission Inventory Conference, US Environmental Protection Agency New Orleans, 15-18 May 2006a.

Chambers, A. and Strosher, M.: Refinery Demonstration of Optical Technologies for Measurement of Fugitive Emissions and for Leak Detection, Final Report, Environment Canada, Ontario Ministry of the Environment and Alberta Environment, 2006b.

Deru, M. and Torcellini, P.: Source Energy and Emission Factors for Energy Use in Buildings, Technical Report NREL/TP-55038617, National Renewable Energy Laboratory, Midwest Research Institute, Battelle, 2006, revised 2007.

Deutscher Bundestag - 17. Wahlperiode: Erdgas-Blowout vor der Küste Schottlands, Drucksache 17/4342, 2010.

Doms, G. and Schättler, U.: A Description of the Nonhydrostatic Regional Model LM, Deutscher Wetterdienst, Technical Report (http://www.cosmo-model.org/), 2002.

EPER: European Pollutant Emission Register 2004, http://eper.ec. europa.eu/, 2004.

European Commision: 2007/589/EC, establishing guidelines for the monitoring and reporting of greenhouse gas emissions pursuant to Directive 2003/87/EC of the European Parliament and of the Council, Official Journal of the European Union, 2007.

Evans, S., Deery, S., and Bionda, J.: How Reliable are GHG Combustion Calculations and Emission Factors, Presented at the CEM 2009 Conference, 23-25 September, Milan, Itlay, 2009.

Forster, P., Ramaswamy, V., Artaxo, P., Berntsen, T., Betts, R., Fahey, D., Haywood, J., Lean, J., Lowe, D., Myhre, G., Nganga, J., Prinn, R., Raga, G., Schulz, M., and Dorland, R. V.: Changes in Atmospheric Constituents and in Radiative Forcing, in: Climate Change 2007: The Physical Science Basis. Contribution of Working Group I to the Fourth Assessment Report of the Intergovernmental Panel on Climate Change, edited by: Solomon, S., Qin, D., Manning, M., Chen, Z., Marquis, M., Averyt, K. B., Tignor, M., and Miller, H. L., 2007.

Frankenberg, C., Meirink, J., Weele, M., Platt, U., and Wagner, T.: Assessing Methane Emissions from Global Space-Borne Observations, Science, 308, 1010-1014, doi:10.1126/science.1106644, 2005.

Gerilowski, K., Tretner, A., Krings, T., Buchwitz, M., Bertagnolio, P. P., Belemezov, F., Erzinger, J., Burrows, J. P., and Bovensmann, H.: MAMAP - a new spectrometer system for columnaveraged methane and carbon dioxide observations from aircraft: instrument description and performance analysis, Atmos. Meas. Tech., 4, 215-243, doi:10.5194/amt-4-215-2011, 2011.

Hess, M., Koepke, P., and Schult, I.: Optical Properties of Aerosols and Clouds: The Software Package OPAC, B. Am. Meteorol Soc., 79, 831-844, 1998.

Livingston, W. and Wallace, L.: An atlas of the solar spectrum in the infrared from 1850 to $9000 \mathrm{~cm}^{-1}$ (1.1 to $\left.5.4 \mu \mathrm{m}\right)$, National 
Solar Observatory, Tech. rep. 91-001, 1991.

Masters, G. M.: Introduction to Environmental Engineering and Science, Prentice-Hall, Inc., 2nd edn., 1998.

Norton, E. G., Vaughan, G., Methven, J., Coe, H., Brooks, B., Gallagher, M., and Longley, I.: Boundary layer structure and decoupling from synoptic scale flow during NAMBLEX, Atmos. Chem. Phys., 6, 433-445, doi:10.5194/acp-6-433-2006, 2006.

NRC: National Research Council (NRC) Committee on Methods for Estimating Greenhouse Gas Emissions, Verifying Greenhouse Gas Emissions: Methods to Support International Climate Agreements, ISBN 0-309-15212-7, available from http: //www.nap.edu/catalog/12883.html, 2010.

Raut, J.-C. and Chazette, P.: Assessment of vertically-resolved $\mathrm{PM}_{10}$ from mobile lidar observations, Atmos. Chem. Phys., 9, 8617-8638, doi:10.5194/acp-9-8617-2009, 2009.

Reuter, M., Buchwitz, M., Schneising, O., Heymann, J., Bovensmann, H., and Burrows, J. P.: A method for improved SCIAMACHY $\mathrm{CO}_{2}$ retrieval in the presence of optically thin clouds, Atmos. Meas. Tech., 3, 209-232, doi:10.5194/amt-3209-2010, 2010.

Ringeval, B., de Noblet-Ducoudré, N., Ciais, P., Bousquet, P., Prigent, C., Papa, F., and Rossow, W. B.: An attempt to quantify the impact of changes in wetland extent on methane emissions on the seasonal and interannual time scales, Global Biogeochem. Cycles, 24, GB2003, doi:10.1029/2008GB003354, 2010.

Rodgers, C. D.: Inverse Methods for Atmospheric Sounding: Theory and Practice, Series on Atmospheric, Oceanic and Planetary Physics - Vol. 2, World Scientific Publishing, 2000.

Rothman, L., Jaquemart, D., , Barbe, A., Benner, D. C., Birk, M., Brown, L., Carleer, M., Jr, C. C., Chance, K., Coudert, L., Dana, V., Devi, V., Flaud, J.-M., Gamache, R., Goldman, A., Hartmann, J.-M., Jucks, K., Makim, A., Mandin, J.-Y., Massie, S., Orphalh, J., Perrin, A., Rinsland, C., Smith, M., Tennyson, J., Tolchenov, R., Toth, R., Auwera, J. V., Varanasi, P., and Wagner, G.: The HITRAN 2004 molecular spectroscopic database, J. Quant. Spectr. Radiat. T., 96, 139-204, doi:10.1016/j.jqsrt.2004.10.008, 2005.

Rothman, L., Gordon, I., , Barbe, A., Benner, D., Bernath, P., Birk, M., boudon, V., Brown, L., Campargue, A., Champion, J.-P., Chance, K., Coudert, L., Dana, V., Devi, V., Fally, S., Flaud, J.-M., Gamache, R., Goldman, A., Jacquemart, D., Kleiner, I., Lacome, N., Lafferty, W., Mandin, J.-Y., Massie, S., Mikhailenko, S., Miller, C., Moazzen-Ahmadi, N., Naumenko, O., Nikitin, A., Orphal, J., Perevalov, V., Perrin, A., PredoiCross, A., Rinsland, C., Rotger, M., Šimečková, M., Smith, M., Sung, K., Tashkun, S., Tennyson, J., Toth, R., Vandaele, A., and Auwera, J. V.: The HITRAN 2008 molecular spectroscopic database, J. Quant. Spectr. Radiat. T., 110, 533-572, doi:10.1016/j.jqsrt.2009.02.013, 2009.
Rozanov, A., Rozanov, V., Buchwitz, M., Kokhanovsky, A., and Burrows, J.: SCIATRAN 2.0 - A new radiative transfer model for geophysical applications in the $175-2400 \mathrm{~nm}$ spectral region, Adv. Space Res., 36, 1015-1019, doi:10.1016/j.asr.2005.03.012, 2005.

Schneising, O.: Analysis and interpretation of satellite measurements in the near-infrared spectral region: Atmospheric carbon dioxide and methane, $\mathrm{PhD}$ thesis, University of Bremen, Institute of Environmental Physics (IUP), Germany, 2009.

Schneising, O., Buchwitz, M., Burrows, J. P., Bovensmann, H., Reuter, M., Notholt, J., Macatangay, R., and Warneke, T.: Three years of greenhouse gas column-averaged dry air mole fractions retrieved from satellite - Part 1: Carbon dioxide, Atmos. Chem. Phys., 8, 3827-3853, doi:10.5194/acp-8-3827-2008, 2008.

Schneising, O., Buchwitz, M., Burrows, J. P., Bovensmann, H., Bergamaschi, P., and Peters, W.: Three years of greenhouse gas column-averaged dry air mole fractions retrieved from satellite - Part 2: Methane, Atmos. Chem. Phys., 9, 443-465, doi:10.5194/acp-9-443-2009, 2009.

Schneising, O., Buchwitz, M., Reuter, M., Heymann, J., Bovensmann, H., and Burrows, J. P.: Long-term analysis of carbon dioxide and methane column-averaged mole fractions retrieved from SCIAMACHY, Atmos. Chem. Phys., 11, 28632880, doi:10.5194/acp-11-2863-2011, 2011.

Shindell, D. T., Faluvegi, G., Koch, D. M., Schmidt, G. A., Unger, N., and Bauer, S. E.: Improved Attribution of Climate Forcing to Emissions, Science, 326, 716-718, doi:10.1126/science.1174760, 2009.

Sutton, O. G.: A Theory of Eddy Diffusion in the Atmosphere, Proceedings of the Royal Society of London. Series A, Containing Papers of a Mathematical and Physical Character, 135, 143-165, 1932.

Trier, A., Cabrini, N., and Ferrer, J.: Correlationis between urban atmospheric light extinction coefficients and fine particle mass concentrations, Atmósfera, 10, 151-160, 1997.

Wuebbles, D. J. and Hayhoe, K.: Atmospheric methane and global change, Earth-Science Reviews, 57, 177-210, doi:10.1016/S0012-8252(01)00062-9, 2002. 